\title{
Desmatamento e a contribuição econômica da floresta na Amazônia
}

\author{
Terciane Sabadini Carvalho \\ Professora - PPGDE/UFPR \\ Endereço: Avenida Prefeito Lothário Meissner, 632 - Jardim Botânico - Curitiba/PR \\ CEP: 80210-170 - E-mail: terciane.carvalho@ufpr.br
}

\author{
Aline Souza Magalhães \\ Professora - Cedeplar/UFMG \\ Endereço: Avenida Antônio Carlos, 6627 - sala 3122 - Belo Horizonte/MG \\ CEP: 31270-901 -E-mail: alinesm@cedeplar.ufmg.br
}

\section{Edson Paulo Domingues}

Professor - Cedeplar/UFMG

Endereço: Avenida Antônio Carlos, 6627 - sala 3046 - Belo Horizonte/MG

CEP: 31270-901 - E-mail: epdomin@cedeplar.ufmg.br

Recebido em 21 de maio de 2013. Aceito em 22 de janeiro de 2016.

\section{Resumo}

Este artigo analisa, do ponto de vista econômico, a contribuição da floresta desmatada para a economia da Amazônia Legal entre 2006 e 2011, assim como os efeitos de uma política de controle do desmatamento entre 2012 e 2020. Para isso, utilizou-se um modelo de equilíbrio geral computável (EGC) inter-regional, construído para capturar as especificidades e heterogeneidade de 103 microrregiões da Amazônia Legal. As simulações da contribuição econômica do desmatamento para essas regiões permitiriam avaliar o custo relativo de políticas de controle, estimando o valor implícito do desmatamento na dinâmica econômica. Os resultados apontam uma contribuição positiva, embora pequena, do desmatamento para o crescimento econômico da Amazônia de 2006 a 2011 . Este resultado é reforçado pelos impactos econômicos de uma política hipotética de controle do desmatamento, que sugerem uma perda apenas marginal sobre o crescimento econômico dessas regiões.

\section{Palavras-Chave}

Equilíbrio geral computável. Amazônia. Desmatamento.

\begin{abstract}
This paper analyzes, from an economic point of view, the contribution of deforestation for the Amazon economy from 2006 to 2011, as well as the effects of a policy to control deforestation from 2012 to 2020 . For this, we used an interregional computable general equilibrium model, built to capture the specificities and heterogeneity of 103 micro-

- Este artigo é uma contribuição da Rede Brasileira de Pesquisas sobre Mudanças Climáticas Globais, convênio FINEP/ RedeCLIMA 01.08.0405.01. O estudo foi realizado no âmbito do projeto "Economia de baixo carbono no Brasil: análise de políticas de redução de gases de efeito estufa", edital Universal CNPQ, processo nº443151/2014-8.
\end{abstract}


-regions of the Amazon. Simulations of the economic contribution of deforestation to the growth of the Amazon would allow assessing the relative cost of control policies, estimating the implicit value of deforestation in economic dynamics. The simulation results indicate a positive contribution of deforestation, however small, for the Amazon economic growth from 2006 to 2011 . This result is reinforced by the economic impacts of a hypothetical policy to control deforestation, suggesting a marginal loss of economic growth in the regions.

\section{Keywords}

Computable general equilibrium. Amazon. Deforestation.

\section{JEL Classification}

Q15. C68. Q58.

\section{Introdução}

O desmatamento na Amazônia Brasileira tem atraído a atenção de pesquisadores e do poder público, em suas diversas esferas, em torno de medidas e políticas que envolvem tanto sua aferição como controle. Dada sua grande biodiversidade, a floresta Amazônica tem sido também pauta de discussões da comunidade internacional, notadamente diante do debate sobre as causas e consequências das mudanças climáticas globais. Além da importância da conservação de um dos maiores biomas de diversidade ecológica (Peres et al., 2010) e, abrigando a maior área de floresta primária do mundo, 35\% do total mundial (FAO, 2010), a região se tornou alvo de políticas de redução de desmatamento para a mitigação das emissões de Gases de efeito Estufa (GEE), uma vez que a maior parte das emissões no Brasil (cerca de $60 \%$ do total em 2005) provém da mudança no uso do solo e florestas (MCT, 2010) ${ }^{\text {}}$.

\footnotetext{
1 A mudança do uso do solo pode ser entendida como a conversão de florestas em áreas para outros fins, como pastagens, agricultura ou outra forma de uso da terra. O processo de desmatamento implica liberação de grande quantidade de dióxido de carbono $\left(\mathrm{CO}_{2}\right)$ para a atmosfera, principalmente através das queimadas e decomposição dos resíduos e liberação do solo. Somente na Amazônia brasileira, na última década, o desmatamento foi responsável pela liberação média de cerca de 200 milhões de toneladas de carbono anuais (3\% do total das emissões globais), não incluindo as emissões por incêndios florestais (Houghton, 2005). Por outro lado, estudos sugerem que a redução nas taxas de desmatamento seria um meio de menor custo para conter as emissões de $\mathrm{CO}_{2}$, comparado ao custo da redução do consumo de combustíveis fósseis nos países mais desenvolvidos (Nordhaus, 1991).
} 
O processo de desmatamento da Amazônia Legal brasileira data notadamente da década de 70 com o início da ocupação da região que incentivou um processo migratório e um consequente adensamento urbano (Ferreira e Salati, 2005; Becker, 2005). Segundo Reis e Margullis (1991), essa expansão foi motivada pela facilidade de crédito, abundância de terras e pelos incentivos fiscais; e reforçada pela relação positiva entre a criação de corredores de acesso à região, a migração e a especulação fundiária. Além disso, a legislação brasileira teria estimulado, de certo modo, o desmatamento, à medida que a reivindicação de terra se dava a partir da comprovação produtiva de seu uso.

Esta relação entre migração e criação de corredores de acesso à região a partir da abertura de estradas é apontada como um dos principais determinantes do desmatamento (Andersen e Reis, 1997; Pfaff, 1997; Nepstad et al., 2001; Soares-Filho et al., 2005). Os resultados encontrados em Nepstad et al. (2001), por exemplo, indicaram que três quartos do desmatamento entre 1978 e 1994 ocorreu dentro de uma faixa de $100 \mathrm{~km}$ de largura ao longo das rodovias BR 010 (Belém-Brasília), BR 364 (Cuiabá-Porto Velho) e PA 150. A densidade demográfica, neste sentido, também contribuiu, representando uma das forças motrizes do desmatamento (Pfaff, 1997; Igliori, 2008).

Estudos sobre a ocupação da Amazônia retratam que, no processo de ocupação de terras da região, pequenos proprietários de terra foram expandindo a fronteira agrícola, sendo, posteriormente, substituídos por uma segunda geração de proprietários, com maior capitalização e ocupando áreas maiores (Souza et al., 2012). Ao mesmo tempo, essa dinâmica forçou os pequenos agricultores a procurarem novas áreas de ocupação, abrindo novas fronteiras para o desmatamento. Neste contexto, a insegurança sobre os direitos de propriedade e regularização das terras (Fearnside, 2005), juntamente com políticas fiscais e creditícias, contribuíram para esse processo de expansão da fronteira agrícola (Binswanger, 1991; Walker et al., 2000; Margullis, 2003; Mertens et al., 2002).

Muitos trabalhos indicam que a pecuária em larga escala é ainda o fator mais relevante (Chomitz e Thomas, 2001; Margulis, 2003; Fearnside, 2005; Castro, 2005; Miragaya, 2008; Rivero et al., 2009; Barona et al., 2010; Oliveira Jr. et al., 2010). Segundo Aguiar et al. 
(2007), a área convertida em pastos corresponde a cerca de $70 \%$ da área total desmatada na região, que atrelada à baixa produtividade foi responsável por estender o arco do desmatamento (Chomitz e Thomas, 2001). Contudo, a expansão da agricultura mecanizada para a produção de grãos, com destaque para a soja e o milho, tem aumentado sua importância no processo recente de expansão da fronteira agrícola em direção às áreas de florestas (Jaramillo e Kelly, 1999; Castro, 2005, Fearnside, 2005; Bickel e Dross, 2003; Carvalho et al., 2002). Estudos indicam que, em termos relativos, a agricultura estaria se expandindo a uma taxa maior do que a pecuária, e que a área de desmatamento na fronteira agrícola foi, em média, o dobro da área para as pastagens, e tal conversão ocorreu muito rapidamente (Morton et al., 2006; Mertens et al. 2002; Kaimowitz et al., 2004). Não obstante, a soja se expandiu em áreas antes ocupadas por pastagens e que, por isso, não representaria um processo de desmatamento novo (Alencar et al., 2004; Laurance et al., 2004).

Segundo o Instituto Nacional de Pesquisas Espaciais (INPE), em agosto de 2011 a área total desmatada ${ }^{2}$ na Amazônia Legal Brasileira ${ }^{3}$

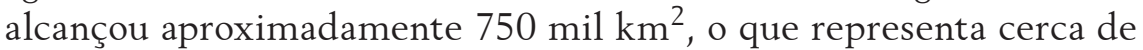
$15 \%$ de sua área geográfica. A maior parte do desmatamento, em torno de 570 mil km² foi observada entre 1977 e 2004 . Ao longo da década de 1990, as taxas anuais de desmatamento situaram-se em torno dos 17 mil km² com ascensão vertiginosa na década de 2000, quando o desmatamento anual alcançou 27 mil km² em 2004 (Soares-Filho et al., 2009). Contudo, desde 2004, o ritmo de desmatamento tem declinado, situando-se em $5,7 \mathrm{mil} \mathrm{km}^{2}$ em 2011, a menor área desmatada medida pelo Programa de Observação do Desmatamento - PRODES (INPE, 2009). Essa queda pode ser associada à influência de fatores econômicos, como a redução dos preços internacionais da soja e da carne e a valorização do Real que desestimulou as exportações. Outro fator para a queda do desmatamento

2 Todavia, deve-se explicar o que se considera como terras "desmatadas". Tradicionalmente, o desmatamento na Amazônia tem sido definido como "a destruição completa e permanente da floresta" para permitir usos alternativos da terra. Isso reflete uma visão de grande parte da literatura que foca na mudança do uso da terra, reconhecendo que a tendência do desmatamento na Amazônia é guiada pela demanda por novas áreas para cultivo ou pasto, diferente do predomínio da demanda por madeira, que ocorre em grande parte da Ásia, ou lenha, como em parte da África (Geist e Lambin, 2002).

3 A Amazônia Legal Brasileira foi instituída por lei (em 1953 no governo Vargas) para fins de planejamento econômico da região amazônica, englobando os Estados do Norte (Acre, Amazonas, Amapá, Pará, Rondônia, Roraima e Tocantins), além do Estado do Mato Grosso e oeste do Maranhão, representando cerca de $60 \%$ do território brasileiro. 
seria o aumento da fiscalização a partir de 2004, com a implementação pelo Governo Federal de programas como o Plano de Ação para a Prevenção e Controle do Desmatamento na Amazônia ${ }^{4}$ (Soares-Filho et al., 2009, Assunção et al., 2012).

O Gráfico 1 ilustra a evolução do desmatamento anual para a Amazônia Legal como um todo e para os estados que a compõem, com destaque para a queda na taxa de desmatamento a partir de 2004. O desmatamento na região é concentrado no chamado "arco do desmatamento", que compreende o sudeste do Maranhão, norte do Tocantins, sul do Pará, norte do Mato Grosso, Rondônia, sul do Amazonas e sudeste do Acre (Ferreira et al., 2005). Entre 2009 e 2011, cerca de $70 \%$ do desmatamento observado no período se concentrou nos estados do Pará e Mato Grosso. O primeiro tem se situado como o estado de maior desmatamento desde 2005, posto ocupado até então pelo estado do Mato Grosso.

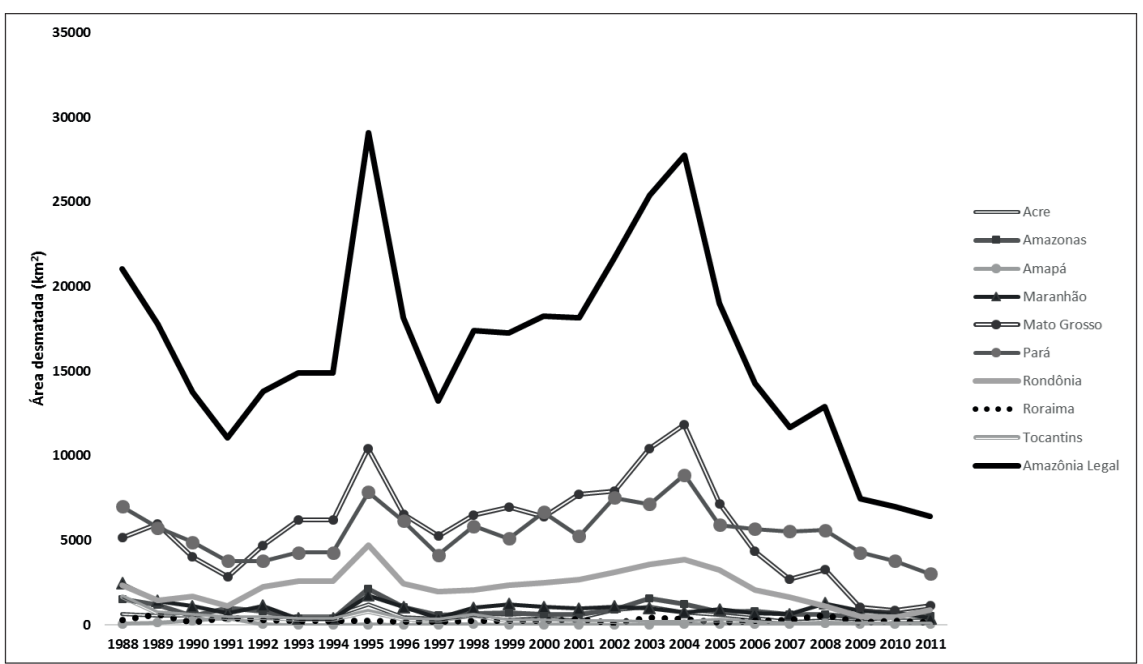

Gráfico 1 - Evolução do desmatamento na Amazônia (1988 - 2011) Km²/ano Fonte: PRODES (INPE).

4 O Plano de Ação para a Prevenção e Controle do Desmatamento na Amazônia Legal (PPCDAM) - lançado em 2004 como resposta governamental às crescentes taxas de desmatamento na Amazônia - tem como objetivo promover a redução das taxas de desmatamento por meio de um conjunto de ações integradas de ordenamento territorial e fundiário, monitoramento e controle ambiental, fomento a atividades produtivas sustentáveis, envolvendo parcerias entre órgãos federais, governos estaduais, prefeituras, entidades da sociedade civil e o setor privado. 
Nesse contexto de redução de desmatamento e negociações de renovação do Protocolo de Quioto, o governo brasileiro apresentou na COP 15, realizada em dezembro de 2009 em Copenhague, metas nacionais voluntárias de reduções de emissões de GEE até 2020 (reduções entre $36,1 \%$ e $38,9 \%$ das emissões projetadas até 2020), ${ }^{6}$ propondo como principal meio, diminuir a taxa de desmatamento da Amazônia em $80 \%$ nesse período (redução estimada de 564 milhões de toneladas de $\mathrm{CO}_{2}$ ).

Parece bastante relevante, dessa forma, investigar aspectos de um provável trade off entre os objetivos de conservação ambiental (redução do desmatamento) e de crescimento econômico na Amazônia Legal. Estimativas da contribuição econômica do desmatamento para o crescimento das regiões da Amazônia Legal permitiriam avaliar, por exemplo, o custo relativo de políticas públicas, como o pagamento de serviços ambientais ou de créditos de carbono por emissões evitadas de GEE. Desse modo, procura-se estimar o valor implícito do desmatamento para a dinâmica econômica das regiões da Amazônia Legal. Estas estimativas são feitas observando-se dois cenários: o desmatamento efetivo na região, de 2006 a 2011; e políticas hipotéticas de controle do desmatamento entre 2012 e 2020.

O objetivo deste artigo é estimar o papel do desmatamento para a economia da Amazônia Legal, considerando sua heterogeneidade setorial e regional. Assim, estima-se a contribuição econômica das áreas desmatadas para o crescimento econômico das regiões na Amazônia Legal em um período recente (2006 a 2011). Posteriormente, são realizadas simulações capturando os impactos econômicos que uma política hipotética de redução do desmatamento teria sobre a economia das regiões da Amazônia Legal. Os números obtidos neste tipo de análise, inéditos para a economia brasileira, podem ser um subsídio para a elaboração de políticas públicas de controle do desmatamento na Amazônia. A metodologia utilizada é a de simulações com a utilização de um modelo de equilíbrio geral computável inter-regional para a economia brasileira, especialmente construída para as regiões da Amazônia.

5 A COP 15 foi a Conferência das Partes, realizada pela UNFCCC - Convenção-Quadro das Nações Unidas sobre Mudança do Clima, de 7 a 18 de dezembro de 2009, em Copenhague (Dinamarca), em que ONGs, empresas e pessoas interessadas discutiram como o mundo pode resolver a ameaça do aquecimento global.

6 Estas metas foram definidas na Política Nacional sobre Mudança do Clima (PNMC), aprovada pelo Congresso Nacional (Lei no 12.187) em 2009. 
Este artigo está dividido em mais quatro seções, além desta introdução. A segunda seção discute a metodologia aplicada ao estudo e a estrutura teórica do modelo REGIA (Interregional General Equilibrium Model for the Brazilian Amazon). ${ }^{7}$ A terceira seção apresenta a base de dados utilizada, o modo de operação do modelo e a descrição das simulações realizadas. Em seguida, têm-se as discussões e análises dos resultados. E por fim, tecem-se as considerações finais.

\section{Metodologia}

\subsection{Modelos de Equilíbrio Geral Computável}

O REGIA é um modelo de Equilíbrio Geral Computável (EGC) bottom-up para as 103 microrregiões da Amazônia Legal (Amazônia) e restante do Brasil. Trata-se do primeiro modelo EGC para as microrregiões brasileiras da Amazônia, trazendo aperfeiçoamentos tanto na sua base de dados como especificação teórica. $\mathrm{O}$ modelo permite analisar como o desmatamento e políticas de controle podem afetar a região da Amazônia em termos setoriais, regionais e macroeconômicos.

Podem-se destacar duas categorias de modelos que têm sido aplicados aos estudos que investigam os impactos econômicos do desmatamento (e seus determinantes) e das mudanças no uso da terra. A primeira categoria consiste em modelos de equilíbrio parcial, que, segundo Mattei (2007), são utilizados para avaliar os efeitos de políticas agrícolas, comerciais ou climáticas no setor agrícola ou florestal, e/ou estudarem os determinantes do desmatamento e das mudanças no uso da terra através de uma mudança exógena nos preços dos produtos agrícolas. No entanto, os modelos de equilíbrio parcial são limitados, pois não consideram como a política afetaria os preços relativos dos insumos e produtos e não conseguem apresentar a distribuição dos impactos econômicos pelos setores e regiões de uma economia.

7 REGIA se refere a uma planta aquática amazônica, a Vitória-régia. Ela possui uma grande folha em forma de círculo, que fica sobre a superfície da água, e pode chegar até 2,5 metros de diâmetro e suportar até 40 quilos se forem bem distribuídos em sua superfície. 
Nesse caso, existe uma segunda categoria que são os modelos de equilíbrio geral computável (ou aplicado), entre os quais se destacam estudos que incorporaram o uso da terra de forma explícita, seja em modelos globais (Darwin et al., 1995), modelos para o Brasil (Ferreira Filho e Horridge, 2011) e mais especificamente, aqueles que abordam o desmatamento na Amazônia (Cattaneo, 2001 e Pattanayak et al., 2010). Cattaneo (2001) examinou a relevância de um conjunto de variáveis mencionadas na literatura como responsáveis pelo desmatamento da Amazônia utilizando um modelo EGC estático regional (Amazônia, Centro-Oeste, Nordeste, restante do Brasil). Entre as simulações realizadas, tem-se: i) desvalorizações na taxa de câmbio real entre $5 \%$ a $40 \%$, ii) abolição dos subsídios agrícolas em todo o país, e iii) uma redução dos custos de transporte. Seu trabalho concluiu que existe um significante trade-off entre a conservação da floresta e o crescimento da agricultura.

Pattanayak et al. (2010) analisaram uma política conhecida como FLONAS, que objetiva expandir em 50 milhões de hectares o sistema nacional de florestas do Brasil, e seus impactos na saúde e na riqueza por meio de um modelo EGC dinâmico de 2010 a 2050. Os principais resultados mostraram que a conservação da floresta se contrapõe aos impactos negativos causados na saúde pelas mudanças climáticas. Entretanto, causa uma pequena perda no PIB e também em outros indicadores (investimentos, exportações e importações). Em relação aos modelos mencionados, o modelo REGIA se diferencia por sua detalhada desagregação regional, 103 microrregiões da Amazônia e restante do Brasil. Pelo que se sabe da literatura, é o modelo com maior detalhamento regional construído para estudar questões relacionadas à Amazônia.

\subsection{O Modelo REGIA: estrutura teórica}

O ponto de partida da especificação do REGIA é um modelo multirregional bottom-up do tipo Johansen, em que a estrutura matemática é representada por um conjunto de equações linearizadas e as soluções são obtidas na forma de taxas de crescimento. Nessa tradição de modelagem também estão outros trabalhos para a economia brasileira, como os modelos B-MARIA (Haddad, 1999) e SPARTA (Domingues, 2002). 
O REGIA é composto por blocos de equações que determinam relações de demanda e oferta, de acordo com hipóteses de otimização e condições de equilíbrio de mercado. ${ }^{8}$ Além disso, vários agregados nacionais são definidos nesses blocos, como nível de emprego agregado, PIB, saldo comercial e índices de preços. Os setores produtivos minimizam os custos de produção sujeitos a uma tecnologia de retornos constantes de escala em que as combinações de insumos intermediários e fator primário (agregado) são determinados por coeficientes fixos (Leontief). Há substituição via preços entre produtos domésticos e importados na composição dos insumos via função de elasticidade de substituição constante (CES). Uma especificação CES também controla a alocação do composto doméstico entre as diversas regiões. Também ocorre substituição entre capital, trabalho e terra na composição dos fatores primários por meio de funções CES, entretanto, o fator terra está alocado apenas nos setores de Agricultura e Pecuária.

Os produtos de uma determinada região direcionados para outra são compostos pelos valores básicos e pelas margens de comércio e transporte. A participação de cada margem no preço de entrega é uma combinação de origem, destino, produto e fonte (doméstico ou importado). As margens sobre os produtos de uma região para outra podem ser fixadas em diferentes regiões. Espera-se que as margens sejam distribuídas mais ou menos equitativamente entre origem e destino, ou entre regiões intermediárias no caso de transporte entre regiões mais distantes. Existe substituição nos fornecedores de margem de acordo com uma função CES.

No modelo, há uma família representativa para cada microrregião, que consome bens domésticos (das microrregiões) e bens importados. A escolha entre domésticos e importados (de outros países) é realizada por uma especificação CES (hipótese de Armington)..$^{9} \mathrm{O}$ tratamento da demanda das famílias é baseado num sistema combinado de preferências CES/Klein-Rubin. Assim, a utilidade derivada do consumo é maximizada segundo essa função de utilidade. Essa especificação dá origem ao sistema linear de gastos (LES), ${ }^{10}$ no qual

8 As equações do modelo REGIA estão descritas no Anexo I deste artigo.

9 Hipótese de Armington - bens de origens diferentes são tratados como substitutos imperfeitos.

${ }^{10} \mathrm{O}$ LES é adequado para amplos agregados de bens onde substituições específicas não são consideradas. Isto é, elasticidades de preços-cruzados são iguais ao efeito renda dado na equação de Slutsky sem qualquer contribuição dos efeitos de pre- 
a participação do gasto acima do nível de subsistência, para cada bem, representa uma proporção constante do gasto total de subsistência de cada família.

Não existe, no modelo, relação fixa entre capital e investimento e essa relação é escolhida de acordo com os requisitos específicos da simulação, conforme explicado na seção 3.1 sobre o fechamento do modelo. As exportações setoriais respondem a curvas de demanda negativamente associadas aos custos domésticos de produção e positivamente afetadas pela expansão exógena da renda internacional, adotando-se a hipótese de país pequeno no comércio internacional. Não há uma teoria para o mercado de trabalho e a relação entre emprego e salário é escolhida conforme os objetivos da simulação, também especificado na seção 3.1. O consumo do governo e a terra, considerado um fator de produção fixo, são exógenos. Como existe substituição entre os fatores primários terra, trabalho e capital, a demanda por terra aumenta em relação aos outros fatores se o seu preço se torna relativamente mais baixo. Portanto, sendo a terra exógena, seu preço se ajusta para equilibrar o mercado de terra.

O REGIA opera com equilíbrio de mercado para todos os bens, tanto domésticos quanto importados, assim como no mercado de fatores (capital, terra e trabalho) em cada microrregião. Os preços de compra para cada um dos grupos de uso em cada região (produtores, investidores, famílias, exportações e governo) são a soma dos valores básicos e dos impostos sobre vendas (diretos e indiretos) e margens (de comércio e transporte). Impostos sobre vendas são tratados como taxas ad-valorem sobre os fluxos básicos. As demandas por margens são proporcionais aos fluxos de bens aos quais as margens estão conectadas.

\section{Base de Dados}

A base de dados do modelo REGIA foi construída por meio de um processo de regionalização da matriz de insumo-produto nacional de 2005. O procedimento partiu da metodologia proposta em Horridge

ço-cruzado. Isso implica que todos os bens são complementares fracos. O sistema linear de gastos não permite a inclusão de bens inferiores (i.e., elasticidades renda negativas). 
(2006), adaptada para o caso brasileiro. A partir dos dados da matriz de insumo-produto de 2005 (110 setores e 110 produtos) e de um grande conjunto de indicadores regionais, estimou-se uma matriz de comércio inter-regional utilizando uma matriz de distâncias e uma abordagem gravitacional. A principal hipótese da abordagem gravitacional $^{11}$ é que o comércio inter-regional está baseado na distância entre as regiões e na interação derivada do tamanho de suas economias. Desse modo, a matriz de comércio foi elaborada assumindo que o volume total de comércio entre duas microrregiões é inversamente proporcional ao quadrado da distância entre elas e diretamente proporcional ao produto do tamanho de ambas, conforme propõe o modelo gravitacional.

Detalhes do procedimento de construção da base de dados do modelo estão em Carvalho (2014). O resultado desse procedimento é a total consistência da base de dados com os dados oficiais das Contas Regionais, Contas Nacionais, Matriz de Insumo-Produto, informações do IBGE; e Comércio Exterior (SECEX), Produção Industrial (PIA) e Emprego (RAIS).

Um dos componentes mais importantes da base de dados para as simulações deste trabalho são a remuneração e uso do fator terra por microrregião na Amazônia Legal. No modelo, o fator terra foi alocado para os setores agricultura e pecuária. A remuneração do fator terra foi obtida a partir dos dados das "Despesas realizadas pelos estabelecimentos - Arrendamento de terras" do Censo Agropecuário de 2006 (IBGE). ${ }^{12}$

${ }^{11}$ Uma difundida justificativa teórica à ideia de que os fluxos bilaterais de comércio dependem positivamente da renda das regiões e negativamente da distância entre elas baseia-se em um modelo de comércio desenvolvido por Krugman (1980). Um maior detalhe do método e algumas aplicações podem ser vistos em Miller e Blair (2009).

${ }^{12}$ A divisão dessa informação entre pecuária e agricultura foi feita de acordo com os valores de arrendamento de terras por grupo de atividade. Por exemplo, para a agricultura foram somados os valores de arrendamento dos grupos: produção de lavoura temporária, horticultura e floricultura, produção de lavouras permanentes, sementes, mudas e outras formas de propagação vegetal e produção florestal. Já para a pecuária foram somados os valores de arrendamento da pecuária e criação de outros animais, pesca e aquicultura. Como a base de dados do modelo é 2005, foi aplicado um deflator para que os valores monetários do Censo se equiparassem aos da matriz de insumo-produto. Assim obteve-se a remuneração da terra em termos nacionais para agricultura e pecuária. O último passo foi dividir a remuneração da terra por microrregião e para isso considerou-se que o valor da mesma é proporcional à produção da agricultura e pecuária em cada região. 


\subsection{Modo de operação do modelo e simulações}

Esta seção apresenta o fechamento do modelo, isto é, as hipóteses adotadas nas simulações. O modelo REGIA possui 26.884 equações e 55.315 variáveis, sendo 28.431 variáveis determinadas exogenamente. $\mathrm{O}$ fechamento define as variáveis que serão determinadas exogenamente e endogenamente nas simulações. Modelos EGC usualmente adotam dois tipos de fechamento, adotando diferentes hipóteses para as variáveis econômicas de acordo com o objeto de estudo. A principal diferença entre os fechamentos está no tratamento do ajuste do estoque de capital e investimento, e no mercado de trabalho. Como o horizonte para as simulações é o período 2006 a 2020, optou-se por utilizar um fechamento específico que se adapta às hipóteses e problemas desta análise.

Portanto, as seguintes hipóteses foram adotadas: i) a oferta de capital é endógena em todos os setores e regiões, com taxas de retorno fixas; ii) o emprego é endógeno e o salário real é exógeno em todas as regiões; iii) a oferta regional do fator terra é exógena e o preço da terra determinado endogenamente (os choques nas simulações alteram a oferta de terra); iv) o investimento nacional é endógeno, obtido pela soma dos investimentos setoriais regionais; v) o consumo real das famílias é endógeno, determinado pela variação da renda do trabalho em cada microrregião; vi) o consumo do governo é exógeno; e vii) as exportações respondem endogenamente ao custo de produção e as importações aos preços relativos e nível de atividade. Assim, o saldo comercial como proporção do PIB é endógeno. 


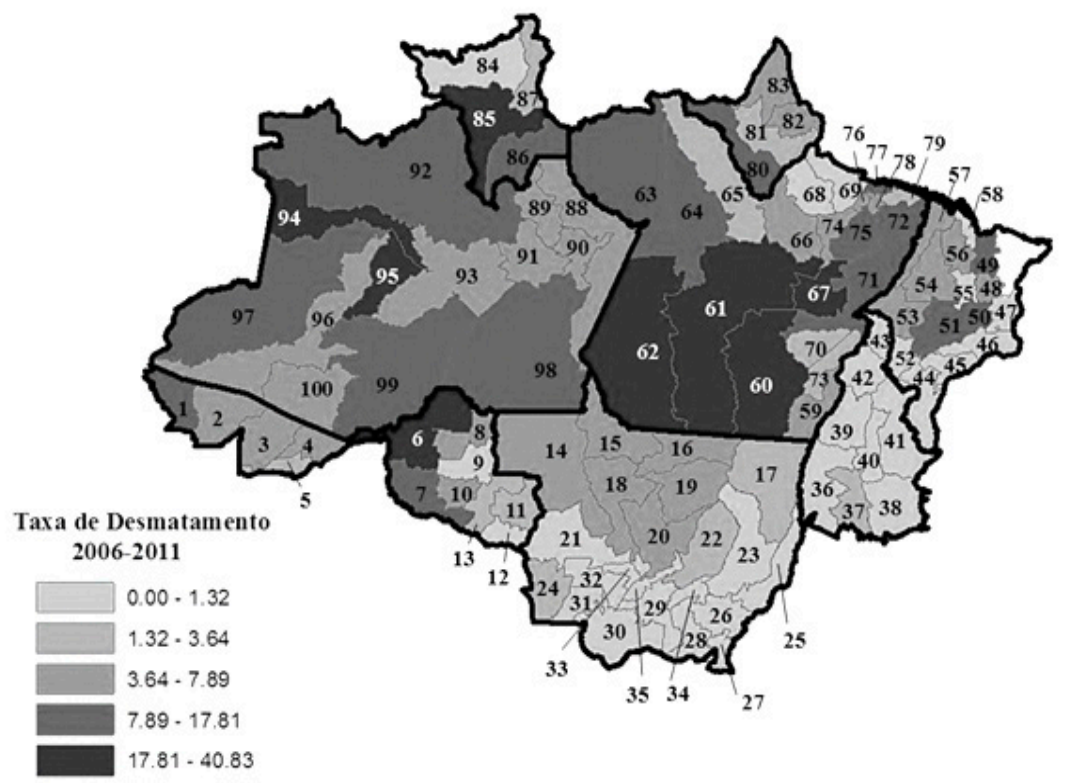

Figura 1 - Taxa de desmatamento regional 2006-2011 (var. \% acumulada em relação à área ocupada pela agropecuária em 2005) ${ }^{13}$

Fonte: Elaboração própria com base nos dados do INPE (2011) e IBGE (2006). Taxa de desmatamento definida como a relação entre a área desmatada $\left(\mathrm{Km}^{2}\right)$ e a área ocupada pela Agricultura e Pecuária $\left(\mathrm{Km}^{2}\right)$.

${ }^{13}$ Lista de microrregiões: 1. Cruzeiro do Sul, 2. Tarauacá, 3. Sena Madureira, 4. Rio Branco, 5. Brasiléia, 6. Porto Velho, 7. Guajará-Mirim, 8. Ariquemes, 9. Ji-Paraná, 10. Alvorada D'Oeste, 11. Vilhena, 12. Colorado do Oeste, 13. Cacoal, 14. Aripuanã, 15. Alta Floresta, 16. Colíder, 17. Norte Araguaia, 18. Arinos, 19. Sinop, 20. Alto Teles Pires, 21. Parecis, 22. Paranatinga, 23. Canarana, 24. Alto Guaporé, 25. Médio Araguaia, 26. Tesouro, 27. Alto Araguaia, 28. Rondonópolis, 29. Cuiabá, 30. Alto Pantanal, 31. Jauru, 32. Tangará da Serra, 33. Alto Paraguai, 34. Primavera do Leste, 35. Rosário do Oeste, 36. Rio Formoso, 37. Gurupi, 38. Dianópolis, 39. Miracema do Tocantins, 40. Porto Nacional, 41. Jalapão, 42. Araguaína, 43. Bico do Papagaio, 44. Gerais de Balsas, 45. Chapadas das Mangabeiras, 46. Chapadas do Alto Itapecuru, 47. Caxias, 48. Codó, 49. Itapecuru Mirim + Rosário + Aglomeração Urbana de São Luís, 50. Presidente Dutra, 51. Alto Mearim e Grajaú, 52. Porto Franco, 53. Imperatriz, 54. Pindaré, 55. Médio Mearim, 56. Baixada Maranhense, 57. Gurupi, 58. Litoral Ocidental Maranhense, 59. Conceição do Araguaia, 60. São Félix do Xingu, 61. Altamira, 62. Itaituba, 63. Óbidos, 64. Santarém, 65. Almeirim, 66. Portel, 67. Tucuruí, 68. Furos de Breves, 69. Arari, 70. Parauapebas + Marabá, 71. Paragominas, 72. Guamá, 73. Redenção, 74. Cametá, 75. Tomé-Açu, 76. Belém, 77. Salgado, 78. Castanhal, 79. Bragantina, 80. Mazagão, 81. Macapá, 82. Amapá, 83. Oiapoque, 84. Boa Vista, 85. Caracaraí, 86. Sudeste de Roraima, 87. Sudeste de Roraima, 88. Parintins, 89. Rio Preto da Eva, 90. Itacoatiara, 91. Manaus, 92. Rio Negro, 93. Coari, 94. Japurá, 95. Tefé, 96. Juruá, 97. Alto Solimões, 98. Madeira, 99. Purus, 100. Boca do Acre. 
A primeira simulação representa a expansão no uso/oferta de terra na Agricultura e Pecuária para as regiões da Amazônia Legal que ocorreu entre os anos de 2006 a 2011, utilizando dados observados de desmatamento para a região. Dessa forma, o intuito é fazer uma estimativa da contribuição do desmatamento ocorrido nesse período sobre o crescimento do PIB e outros agregados macroeconômicos. ${ }^{14}$ Assim, para cada microrregião da Amazônia Legal (103 regiões), a expansão no uso da terra foi calculada utilizando dados de área desmatada em relação à área ocupada pela agropecuária no período de 2006 a 2011, como retratado na Figura 1. Assume-se, por hipótese, que essa área é integralmente utilizada para a expansão da agricultura e da pecuária. ${ }^{15}$

A área desmatada foi obtida através de dados do INPE (INPE, 2011) de desmatamento anual e a área ocupada pelas atividades de Agricultura e Pecuária pelos dados do Censo Agropecuário (IBGE, 2006). Observa-se, pela Figura 1, que as regiões que apresentaram a maior taxa de desmatamento foram Altamira (61), São Félix do Xingu (60), Itaituba (62), Caracaraí (85) e Japurá (94).

A segunda simulação avalia o impacto de uma política de controle de desmatamento na Amazônia entre 2012 e 2020. O choque representa uma política de controle de desmatamento em que cada microrregião pode alcançar entre $25 \%$ a $100 \%$ de redução do desmatamento projetado no cenário de Bittencourt (2011). ${ }^{16}$ Como o modelo de Bittencourt (2011) apresenta a tendência do desmatamento em $\mathrm{km}^{2}$ de 2008 a 2020, foram utilizados dados do INPE (2011) de ocupação e uso do solo para 2008 como base de referência para a área ocupada pela agricultura e pecuária. A justificativa para um intervalo de re-

${ }^{14}$ O objetivo deste cenário é isolar o efeito que o desmatamento observado no período de 2006 a 2011 teve na economia da Amazônia Legal. Com esta simulação, consegue-se avaliar qual foi o crescimento econômico do período que seria o resultado da incorporação de mais terra (via desmatamento) para a agropecuária na região em relação a um cenário contrafactual que não compreende a variação observada do desmatamento durante o período.

${ }^{15}$ Assim, desconsideram-se áreas desmatadas que poderiam ter sido utilizadas para outros fins, como ocupação para moradia (urbana ou assentamentos), obras de infraestrutura (estradas, hidroelétricas) ou mesmo como forma de posse da terra.

16 Este trabalho utilizou uma modelagem dinâmica espacial para a distribuição de metas de redução do desmatamento para os municípios da Amazônia Legal brasileira, e estimou o potencial de redução de GEEs e de receitas financeiras advindas de um futuro mecanismo de REDD+. O modelo levou em consideração a Política Nacional de Mudanças Climáticas (PNMC) e os planos publicados de combate ao desmatamento dos estados do Acre, Amazonas, Mato Grosso e Pará. Para alcançar os seus objetivos, o autor utilizou mapas georreferenciados como variáveis explicativas e simulou a tendência do desmatamento de 2006 a 2020, com um modelo dinâmico desenvolvido no software Dinâmica Ego. 
dução de desmatamento é que existe incerteza tanto nas metas das políticas como no próprio cenário de desmatamento. Para trabalhar com intervalos de choques foi utilizado o procedimento de análise sensibilidade sistemática (SSA- Systematic Sensitive Analysis) do GEMPACK, que permite avaliar a robustez dos resultados obtidos nas simulações em relação aos valores dos choques. ${ }^{17}$ Todo o procedimento computacional foi realizado no software GEMPACK.

A Figura 2 ilustra o choque de política de controle do desmatamento entre 2012 e 2020 em relação à área ocupada total de cada microrregião para o caso de desmatamento zero. A região que apresentaria a maior meta de redução de desmatamento ao ano, no caso de desmatamento zero, segundo estas projeções, seria a Aglomeração Urbana de São Luís (49) (mais de 29\% a.a.), seguido por Rio Preto da Eva (89) com 23,18\% a.a., Rosário (49), em torno de 16\% a.a. e Manaus (91) (8\% a.a.). Após, tem-se regiões como Arari (69) e Almeirim (65) no Pará, Juruá (96), Madeira (98) e Itacoatiara (90) no Amazonas, Itapecuru Mirim (49) e Chapada do Alto Itapecuru (46) no Maranhão, todas apresentando metas acima de 5\% a.a.

${ }^{17}$ Detalhes desse procedimento em DeVuyst e Preckel (1997). O procedimento de cálculo para o choque foi, primeiramente, uma simulação com um choque de $50 \%$ da taxa de desmatamento zero. Depois disso, a SSA foi feita com um intervalo de 0,5 e duas vezes esse choque. Desse modo, os resultados obtidos refletem um resultado médio de simulações hipoteticamente realizadas em todo esse intervalo. A simulação assumiu um intervalo de $50 \%$ para a redução do desmatamento, com distribuição uniforme e simétrica. Os intervalos de confiança foram obtidos a partir dos resultados de média e desvio-padrão produzidos pela análise de sensibilidade sistemática (SSA), usando a desigualdade de Chebychev (Greene, 2003) que estabelece limites de aproximadamente três desvios-padrão a partir da média, para um intervalo de confiança de $90 \%$. De forma genérica, pode-se concluir que determinado resultado é mais sensível (menos robusto) ao choque se seu desvio padrão está relativamente próximo da respectiva média, de forma que o intervalo de confiança muda de sinal (Domingues, 2002). Nas simulações realizadas para este estudo, significa testar a possibilidade do choque assumir diferentes valores dentro do intervalo considerado de redução do desmatamento. Portanto, se ocorre mudança de sinal para alguma variável significa que ela pode aumentar ou diminuir dependendo da taxa de redução de desmatamento que for adotada pela política. 


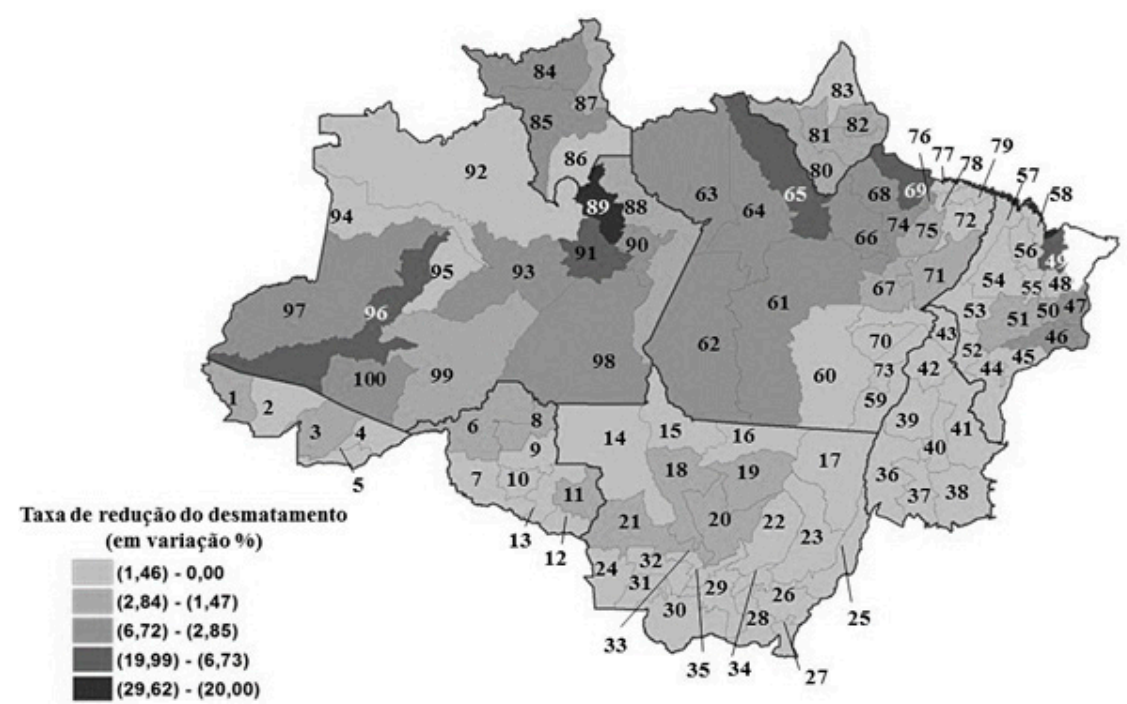

Figura 2 - Taxa média de Redução do Desmatamento na Amazônia Legal (variação \% a.a. para o período de 2012 a 2020 em relação ao cenário base de desmatamento)

Fonte: Elaboração própria com base nos dados de Bittencourt (2011) e INPE (2011)

Essa política de controle representa, hipoteticamente, uma restrição nas possibilidades de expansão da oferta de terra. De acordo com os mecanismos do modelo, o impacto direto seria um aumento da remuneração da terra e consequentemente elevação do custo de produção dos bens agropecuários. Isso diminui o nível de atividade do setor e da sua cadeia produtiva (insumos). Naturalmente, esta restrição de terra gera impactos mais intensos sobre as regiões que têm sua economia baseada na agropecuária. A Figura 3 mostra a direção desses mecanismos de causalidade do modelo REGIA.

O bem-estar das famílias é afetado tanto pela elevação dos preços dos produtos como pela redução do emprego e da renda. Como o modelo é inter-regional, a restrição do desmatamento também provoca uma realocação da produção em direção às regiões menos prejudicadas. Estes impactos são consistentemente projetados pelo modelo REGIA visto que leva em conta a interdependência regional. Outro efeito capturado pelo modelo é o movimento para substituição da terra em direção a outros fatores produtivos (capital e trabalho). Entretanto, o modelo adota que esta substituição 
se dá sempre a custos crescentes, pois os insumos são substitutos imperfeitos. Empiricamente, sabe-se que a terra na Amazônia é um fator relativamente abundante e de baixo custo, comparativamente a trabalho e, especialmente, capital (máquinas e equipamentos). Reconhecidamente, pequenos proprietários na Amazônia não têm os recursos necessários para investir em diferentes métodos de produção e optam pelas queimadas e derrubadas da floresta para ampliarem a produção. Uma política de controle reduziria esta possibilidade e aumentaria seus custos de produção, como capturado pelo modelo.

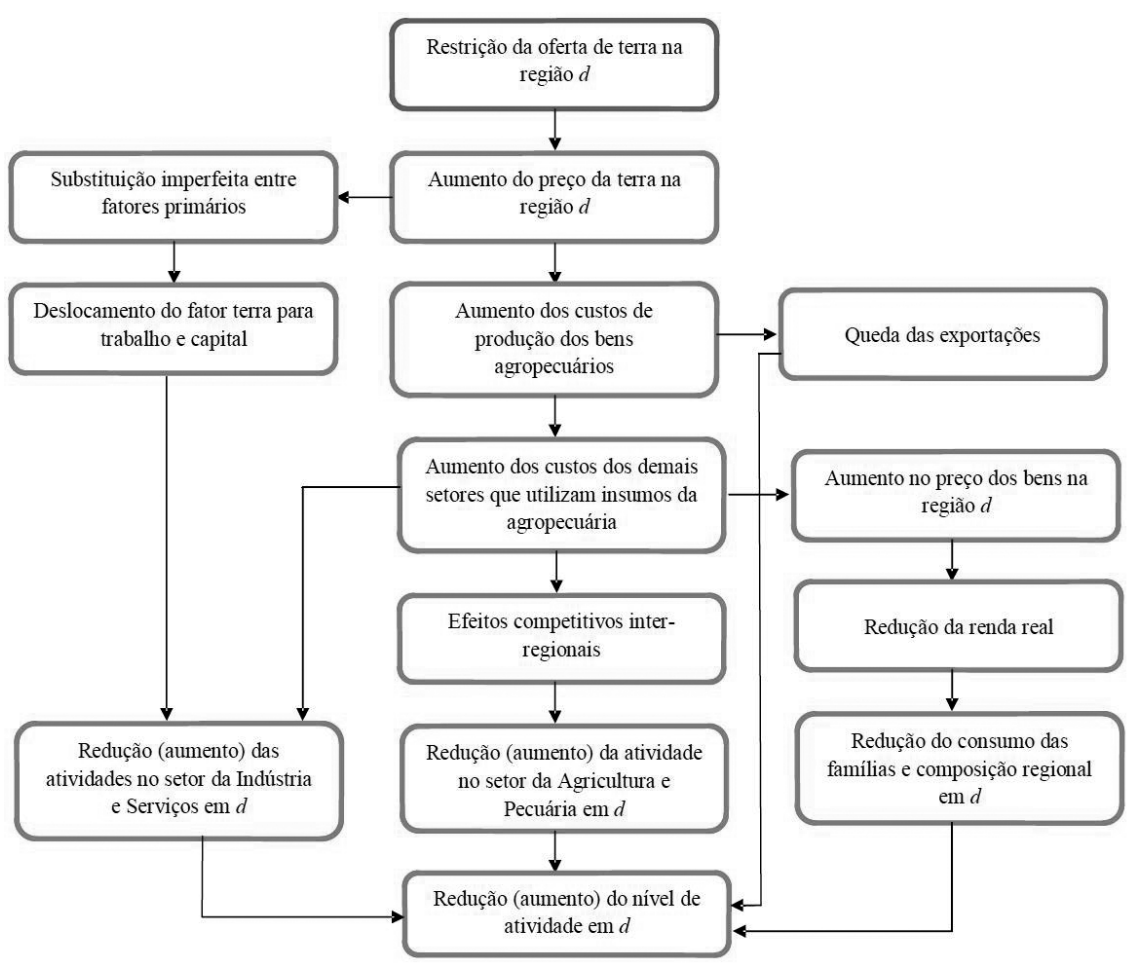

Figura 3 - Mecanismos de Causalidade do Modelo REGIA

Fonte: Elaboração própria.

\section{Resultados e discussões}

A Tabela 1 apresenta os resultados das simulações para PIB e emprego das 20 maiores regiões em área de desmatamento de 2006 a 2011, 
que representaram cerca de $70 \%$ do desmatamento no período, e concentram-se nos estados do Pará e Mato Grosso. Os resultados devem ser lidos como desvios em relação a uma trajetória da economia brasileira (cenário base) na qual a expansão do uso/oferta de terra (desmatamento) não ocorresse.

Observa-se pelos resultados que o desmatamento teria pequenos efeitos positivos sobre o PIB e emprego das regiões (deve-se notar que a magnitude dos impactos se referem a um período de seis anos, 2006 a 2011). Assim, os resultados indicam que em Altamira (PA), por exemplo, o desmatamento teria contribuído para um acréscimo de somente $0,87 \%$ no PIB e $0,59 \%$ no emprego, relativamente a uma situação em que o desmatamento não tivesse ocorrido.

Cabe ressaltar que a relação entre os choques e os impactos econômicos não é linear, no sentido de que nem sempre as regiões com maior desmatamento são aquelas com a estimação de maiores impactos projetados pelo modelo. São Félix do Xingu, por exemplo, apresenta um choque de desmatamento maior $(25,8 \%)$ que Altamira $(22,8 \%)$ e, no entanto, o efeito sobre o PIB e emprego em São Félix do Xingu seria menor. Tendo em vista as estruturas produtivas distintas, o resultado é explicado pela dinâmica das exportações de Altamira, que teria importante parcela de contribuição sobre o efeito positivo na região. Itaituba (PA) também estaria entre as regiões mais beneficiadas pelo desmatamento (choque de 33,7\%), e nesse caso o impacto positivo nas exportações explicam a contribuição positiva sobre o PIB e emprego.

Tabela 1 - Resultados das simulações: efeito do desmatamento entre 2006 e 2011 sobre o PIB e o Emprego, para as 20 maiores regiões em área de desmatamento

\begin{tabular}{|c|c|c|c|c|c|c|c|c|c|}
\hline \multirow{2}{*}{ Microrregião } & \multirow{2}{*}{ Es tado } & \multirow{2}{*}{$\begin{array}{c}\text { Des matamento } \\
\mathrm{Km} 2\end{array}$} & \multirow{2}{*}{$\frac{\text { PIB }}{\text { (var. \%) }}$} & \multirow{2}{*}{$\begin{array}{l}\text { Emprego } \\
\text { (var. \%) }\end{array}$} & \multirow{2}{*}{ Microrregião } & \multirow[t]{2}{*}{ Estado } & \multirow{2}{*}{$\begin{array}{c}\text { Des matamento } \\
\mathrm{Km} 2\end{array}$} & \multirow{2}{*}{$\frac{\text { PIB }}{\text { (var. \%) }}$} & \multirow{2}{*}{$\frac{\text { Emprego }}{\text { (var. \%) }}$} \\
\hline & & & & & & & & & \\
\hline Altamira & PA & 5106,4 & 0,87 & 0,59 & Alta Floresta & MT & 1243,7 & 0,40 & 0,32 \\
\hline São Félix do Xingu & PA & 4386,9 & 0,68 & 0,38 & Marabá & PA & 1201,7 & 0,35 & 0,35 \\
\hline Tucuruí & PA & 3241,7 & 0,55 & 0,45 & Santarém & PA & 1187,7 & 0,45 & 0,38 \\
\hline Porto Velho & RO & 3104,4 & 0,54 & 0,47 & Colíder & MT & 1120,5 & 0,30 & 0,26 \\
\hline Itaituba & PA & 2861,7 & 0,86 & 0,56 & Tomé-Açu & PA & 1116,4 & 0,53 & 0,39 \\
\hline Aripuanã & MT & 2294,7 & 0,47 & 0,35 & Guamá & PA & 1100,9 & 0,40 & 0,29 \\
\hline Paragominas & PA & 1679,4 & 0,58 & 0,41 & Alto Mearime Grajaú & MA & 1078,1 & 0,37 & 0,28 \\
\hline Norte Araguaia & MT & 1624,7 & 0,25 & 0,20 & Arinos & MT & 1045,5 & 0,78 & 0,54 \\
\hline Sinop & MT & 1265,4 & 0,55 & 0,47 & Madeira & $\mathrm{AM}$ & 1009,6 & 0,51 & 0,35 \\
\hline Conceição do Araguaia & PA & 1248,2 & 0,37 & 0,25 & Alto Teles Pires & MT & 957,2 & 0,68 & 0,51 \\
\hline
\end{tabular}

Fonte: Elaboração própria com base nos resultados do modelo REGIA. As regiões do quadro representam 70\% desmatamento observado entre 2006 e 2011. 
Outra microrregião de destaque é Arinos (MT) que observou área desmatada de 1045,5 $\mathrm{km}^{2}$, em média, entre 2006-2011 (choque nas simulações de apenas $4,86 \%$ ), e apresentou um crescimento significativo no PIB e emprego (0,78\% e $0,54 \%$, respectivamente). Contribuiriam para este resultado o elevado aumento no consumo das famílias e das exportações nesta região, e o fato de que a sua estrutura produtiva se concentra no setor agrícola, responsável por quase $60 \%$ da sua atividade econômica.

A Figura 4 ilustra a contribuição do desmatamento para o PIB, produção da agricultura e pecuária nas regiões da Amazônia. As partes mais escuras da figura indicam as regiões que mais se beneficiariam com o desmatamento. Além do padrão anteriormente apontado para as regiões de Altamira, São Félix do Xingu, Itaituba e Arinos, observa-se também maiores taxas de crescimento do PIB em regiões como Purus (AM), Caracaraí (RR), Alto Teles Pires (MT), Paragominas (PA) e Tucuruí (PA). Algumas regiões, em tons mais claros, teriam redução da atividade econômica mesmo com desmatamento, como Rio Formoso (TO), Tesouro (MT), Primavera do Leste (MT) a Alto Araguaia (MT), em razão, sobretudo, do desmatamento menos intenso (choques relativamente menores) e dos efeitos competitivos provocados pelas regiões mais beneficiadas com o processo.
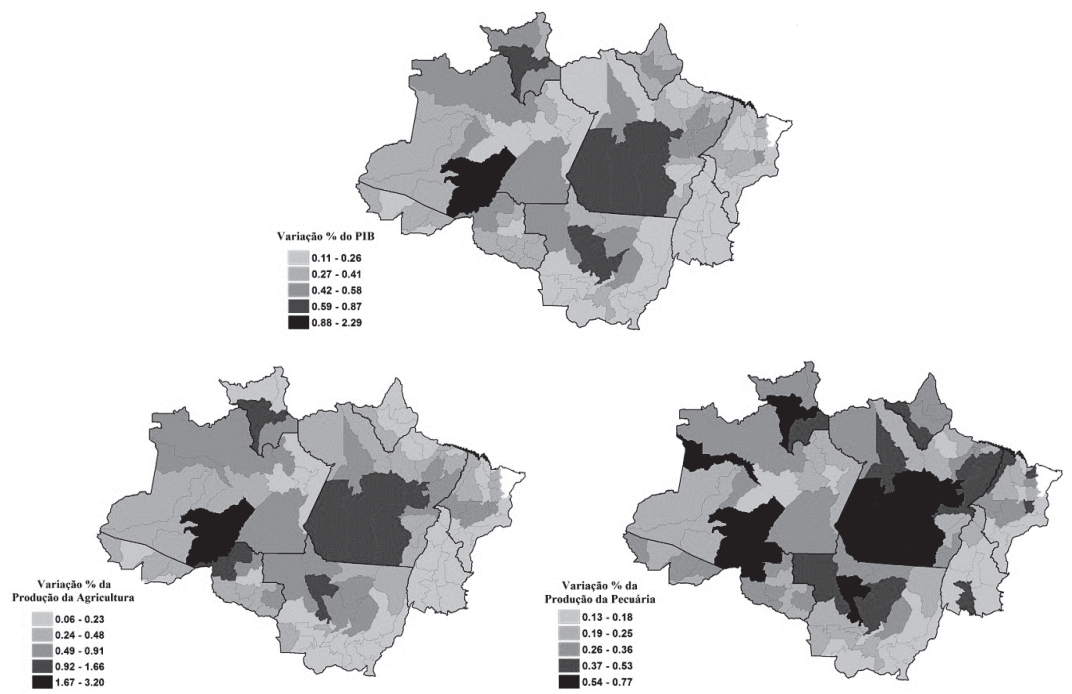

Figura 4 - Resultados das simulações: efeito do desmatamento de 2006 a 2011 sobre o PIB e a produção da Agricultura e Pecuária (var. \% acumulada)

Fonte: Elaboração própria com base nos resultados do modelo REGIA. 
Em relação ao impacto do desmatamento na produção, destacamse as regiões de Purus (AM), Tucuruí (PA), São Félix do Xingu (PA), Itaituba (PA), Altamira (PA), Porto Velho (RO) Arinos (MT) e Caracaraí (RR) com um crescimento acima de $1 \%$ no setor de Agricultura e de 0,50\% na Pecuária. Os impactos sobre o emprego e exportações, por sua vez, podem ser visualizados na Figura 5.

A dinâmica do emprego tende a acompanhar o padrão verificado pelo crescimento do PIB, destacando-se as regiões de Purus, Caracaraí, Altamira, Itaituba e Arinos. Além destas, a microrregião de Macapá (AP) também se destaca com crescimento acima de 0,5\% do emprego agregado. As maiores taxas de crescimento das exportações se encontram em Tucuruí (PA), Sinop (MT), Tomé-Açu (PA), Marabá (PA), Arari (PA) e Belém (PA). Tucuruí, Sinop e Tomé-Açu aumentariam principalmente suas exportações agropecuárias, enquanto Marabá, Belém e Arari apresentariam crescimento em setores diversos.

Os resultados apontam para um fato importante da estrutura econômica e do desmatamento nas regiões da Amazônia: a baixa contribuição econômica do desmatamento na perspectiva do aumento da disponibilidade de terras para a agricultura e pecuária. Ou seja, a facilidade de incorporação desse fator produtivo (terra via desmatamento) desincentiva a incorporação de trabalho e capital ao processo produtivo desses setores, contribuindo para sua reconhecida condição de baixa produtividade e competitividade.
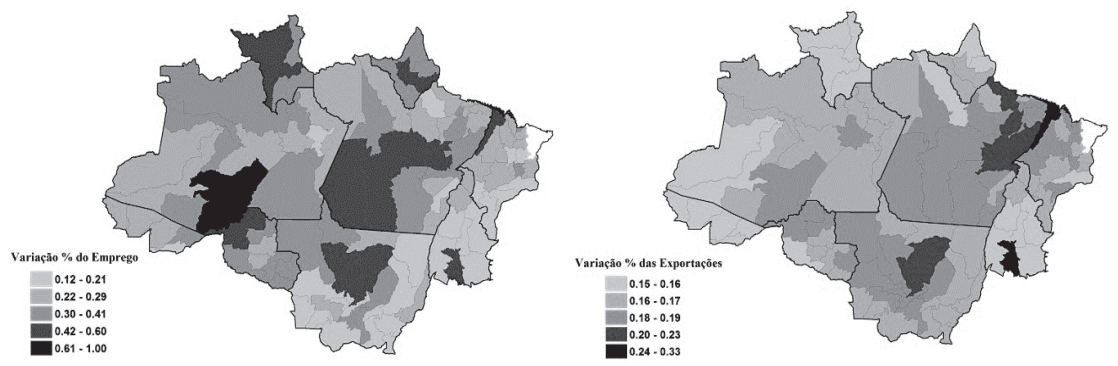

Figura 5 - Resultados das simulações: efeito do desmatamento de 2006 a 2011 sobre emprego e exportações (var. \% acumulada)

Fonte: Elaboração própria com base nos resultados do modelo REGIA. 
A Tabela 2 reporta os impactos agregados do desmatamento entre 2006 a 2011. Como esperado a partir dos resultados regionais, observa-se uma variação positiva nos principais agregados macroeconômicos, tanto na escala nacional quanto regional (Amazônia Legal).

Tabela 2 - Resultados das simulações: efeito do desmatamento de 2006 a 2011 no Brasil e na Amazônia (Var. \% acumulada)

\begin{tabular}{lccc}
\hline Variaveis & Brasil & Amazônia Legal & Resto do Brasil \\
\hline PIB & $\mathbf{0 , 1 4 2}$ & 0,313 & 0,125 \\
Emprego & $\mathbf{0 , 1 5 3}$ & 0,295 & 0,141 \\
Investimento & $\mathbf{0 , 1 2 5}$ & 0,255 & 0,113 \\
Exportação & $\mathbf{0 , 1 4 3}$ & 0,176 & 0,141 \\
Deflator do PIB & $\mathbf{- 0 , 0 0 4}$ & $-0,118$ & 0,007 \\
\hline
\end{tabular}

Fonte: Elaboração própria com base nos resultados do modelo REGIA.

Os resultados apontam que o desmatamento teria contribuído com apenas 0,142\% do crescimento do PIB brasileiro entre 2006 e 2011. Para uma dimensão relativa desse número, considerando o PIB brasileiro de 2011 (cerca de quatro trilhões de reais), o desmatamento na Amazônia entre 2006 e 2011 teria acrescido ao PIB nacional um montante de $\mathrm{R} \$ 5,9$ bilhões, ou 75,3 mil reais por cada $\mathrm{km}^{2}$ desmatado. Novamente, confirma-se aqui a baixa contribuição do desmatamento para a economia brasileira, que certamente não compensa seu custo em termos de degradação ambiental, perda de biodiversidade e serviços ecossistêmicos.

Destes $\mathrm{R} \$ 5,9$ bilhões, aproximadamente 55\%, são internalizados na Amazônia, ao passo que os outros $45 \%$ são absorvidos (efeito de vazamento) pelo resto do Brasil. Ou seja, o desmatamento da Amazônia gera efeitos econômicos quase tão intensos no resto do Brasil como na própria região, fruto da inter-relação entre elas.

Observa-se pela Tabela 3 que o emprego e o investimento agregado apresentam uma variação positiva seguindo o aumento da atividade econômica. As exportações também apresentaram variação positiva, pois a queda dos preços dos produtos nacionais torna os produtos exportados relativamente mais baratos.

As simulações permitem ainda estimar um resultado interessante para políticas complementares ao controle de desmatamento, como de melhorias de tecnologia e processos produtivos na agricultura 
e pecuária. O aumento da produtividade da terra para se obter a mesma variação estimada do PIB nacional seria de $6,68 \%$ no período. Assim, essa elevação de produtividade ${ }^{18}$ na agropecuária teria o mesmo impacto de crescimento do PIB nacional que o desmatamento de 2006 e 2011. Segundo Gasques et al. (2008), a produtividade da terra no Brasil cresceu 3,26\% ao ano entre 2000 e 2005, indicando que esta taxa seria factível, pois é de pouco mais de $1 \%$ ao ano.

\subsection{Política de controle de desmatamento 2012-2020}

Hipoteticamente, uma política de controle de desmatamento limita a expansão relativa da área ocupada pela agropecuária. Essa restrição na oferta de terra torna esse fator mais caro e provoca uma substituição do mesmo em direção a trabalho e capital. A maior demanda por esses fatores, por sua vez, eleva o seu preço, gerando um aumento de custos da produção. $\mathrm{O}$ aumento de custos no setor agropecuário torna seu produto mais caro, acarretando um aumento de custo aos demais setores (que usam esses produtos como insumos) e agentes (consumidores, exportadores e governo). Assim, a restrição na expansão da oferta de terra na Amazônia teria impactos negativos afetando mais as regiões que têm sua economia voltada para a agropecuária. Os resultados para PIB e emprego das 20 maiores regiões em área de desmatamento, de acordo com o cenário de Bittencourt (2011) para o período 2012-2020, estão na Tabela 2, assim como os valores dos intervalos de confiança a $90 \%$, mostrando a variabilidade do resultado dentro do intervalo (entre $25 \%$ a $100 \%$ de redução de desmatamento). ${ }^{19}$

${ }^{18}$ Para o cálculo da produtividade requerida foi realizada uma simulação cujo choque representava um aumento de $1 \%$ sobre a produtividade da terra nas microrregiões da Amazônia Legal. Essa simulação gerou o resultado de impacto sobre o PIB agregado devido a esta elevação da produtividade. A produtividade necessária, então, para se alcançar o mesmo crescimento verificado quando de um aumento na expansão da oferta de terra pôde ser calculada como a razão entre o impacto do PIB na simulação de expansão da oferta da terra $(0,142)$ e o impacto sobre a mesma variável na simulação de aumento da produtividade $(0,021)$.

${ }^{19}$ As elasticidades e os parâmetros do modelo foram testados por meio da análise de sensibilidade (SSA) e se mostraram robustos para um intervalo de 50\% dos parâmetros de substituição de fatores primários (capital, trabalho e terra). 
Este conjunto de regiões representaria cerca de 65\% do desmatamento total do cenário e concentra-se nos estados do Pará, Mato Grosso e Rondônia. Conforme observa-se pelos resultados, a restrição da oferta de terra teria efeitos negativos sobre o PIB da maioria das regiões e positivo sobre o emprego. Nota-se que a magnitude dos impactos é pequena mesmo quando os resultados são apresentados para o período de nove anos. Assim, os resultados indicam que o controle da oferta de terra em Aripuana, por exemplo, representaria um decréscimo de $0,23 \%$ no PIB e um acréscimo de 0,56\% no emprego da região. Porto Velho e Vilhena apresentariam um aumento do PIB, porém conforme se observa pela Tabela 3 , o PIB poderia ser negativo se a meta de controle do desmatamento na região fosse mais elevada.

Tabela 3 - Resultados das simulações: efeito do controle do desmatamento sobre PIB e Emprego para as 20 maiores regiões em área de desmatamento (variação \% acumulada de 2012 a 2020)

\begin{tabular}{|c|c|c|c|c|c|c|c|c|}
\hline \multirow{3}{*}{$\begin{array}{l}\text { Microrregião } \\
\text { Aripuana }\end{array}$} & \multirow{3}{*}{$\begin{array}{c}\text { Estado } \\
\text { MT }\end{array}$} & \multirow{3}{*}{$\begin{array}{c}\text { Des matamento } \\
\mathbf{K m} 2 \\
816,44\end{array}$} & \multicolumn{3}{|c|}{ PIB } & \multicolumn{3}{|c|}{ Emprego } \\
\hline & & & \multirow{2}{*}{$\begin{array}{c}\text { Variação } \\
(\mathbf{\%})\end{array}$} & \multicolumn{2}{|c|}{$\begin{array}{c}\text { Intervalo de } \\
\text { Confiança }(\mathbf{9 0 \%}) \\
\end{array}$} & \multirow{2}{*}{$\frac{(\text { var. \%) }}{0,557}$} & \multicolumn{2}{|c|}{$\begin{array}{c}\text { Intervalo de Confiança } \\
(\mathbf{9 0 \% )}\end{array}$} \\
\hline & & & & $-0,362$ & $-0,180$ & & 0,260 & 0,855 \\
\hline Altamira & PA & 742,67 & $-0,240$ & $-0,385$ & $-0,187$ & 0,468 & 0,231 & 0,705 \\
\hline Itaituba & PA & 638,67 & $-0,181$ & $-0,284$ & $-0,168$ & 0,298 & 0,168 & 0,428 \\
\hline Porto Velho & $\mathrm{RO}$ & 623,11 & 0,039 & 0,015 & $-0,027$ & 0,223 & 0,125 & 0,310 \\
\hline Arinos & MT & 567,78 & $-0,289$ & $-0,466$ & $-0,203$ & 0,719 & 0,297 & 1,142 \\
\hline Sinop & MT & 519,33 & $-0,127$ & $-0,206$ & $-0,138$ & 0,613 & 0,255 & 0,972 \\
\hline São Félix do Xingu & $\mathrm{PA}$ & 494,44 & $-0,110$ & $-0,171$ & $-0,139$ & 0,079 & $-0,006$ & 0,163 \\
\hline Santarém & $\mathrm{PA}$ & 451,11 & $-0,164$ & $-0,270$ & $-0,149$ & 0,346 & 0,178 & 0,515 \\
\hline Norte Araguaia & MT & 446,67 & $-0,122$ & $-0,195$ & $-0,140$ & 0,129 & 0,074 & 0,183 \\
\hline Paragominas & $\mathrm{PA}$ & 399,11 & $-0,141$ & $-0,227$ & $-0,146$ & 0,214 & 0,107 & 0,320 \\
\hline Alta Floresta & MT & 386,22 & $-0,132$ & $-0,209$ & $-0,145$ & 0,136 & 0,067 & 0,205 \\
\hline Alto Teles Pires & MT & 329,56 & $-0,167$ & $-0,269$ & $-0,155$ & 0,544 & 0,215 & 0,873 \\
\hline Colíder & MT & 268,44 & $-0,096$ & $-0,154$ & $-0,129$ & 0,057 & 0.000 & 0,114 \\
\hline Óbidos & $\mathrm{PA}$ & 256,89 & $-0,123$ & $-0,198$ & $-0,139$ & 0,259 & 0,141 & 0,377 \\
\hline Tucuruí & $\mathrm{PA}$ & 249,56 & $-0,056$ & $-0,094$ & $-0,108$ & 0,016 & 0,002 & 0,031 \\
\hline Parecis & MT & 236,67 & $-0,296$ & $-0,479$ & $-0,204$ & 1,648 & 0,626 & 2,681 \\
\hline Portel & $\mathrm{PA}$ & 220,22 & $-1,780$ & $-2,991$ & $-0,690$ & 6,735 & 2,199 & 11,527 \\
\hline Vilhena & $\mathrm{RO}$ & 203,56 & 0,048 & 0,027 & $-0,021$ & 0,180 & 0,098 & 0,261 \\
\hline Tomé-Açu & PA & 200,00 & $-0,197$ & $-0,315$ & $-0,169$ & 0,195 & 0,078 & 0,311 \\
\hline Ariquemes & $\mathrm{RO}$ & 198,67 & $-0,035$ & $-0,072$ & $-0,088$ & 0,135 & 0,077 & 0,192 \\
\hline
\end{tabular}

Fonte: Elaboração própria com base nos resultados do modelo REGIA. 
A Figura 6 ilustra o impacto sobre o PIB e a produção nos setores de agricultura e pecuária. Esses resultados refletem um resultado médio de simulações realizadas em todo o intervalo de $25 \%$ a $100 \%$ do desmatamento. As partes mais escuras do mapa indicam as regiões que mais perderiam e as regiões mais claras apresentaram alguns casos de impacto positivo. Portel teria a maior redução no PIB, $-1,79 \%$, seguido por Furos dos Breves (-1,40\%) e Arari (-0,93\%). O setor de agricultura se destaca em Portel, responsável por mais de $80 \%$ da produção da região. Furos dos Breves apresenta mais de 50\% de sua produção na agricultura, enquanto Arari apresenta economia voltada para a pecuária, com mais de $60 \%$ do total produzido. As três regiões apresentam elevadas taxas de desmatamento, de acordo com o cenário de referência de Bittencourt (2011), o que significa que apresentam elevadas restrições de oferta de terra nas simulações de controle do desmatamento.

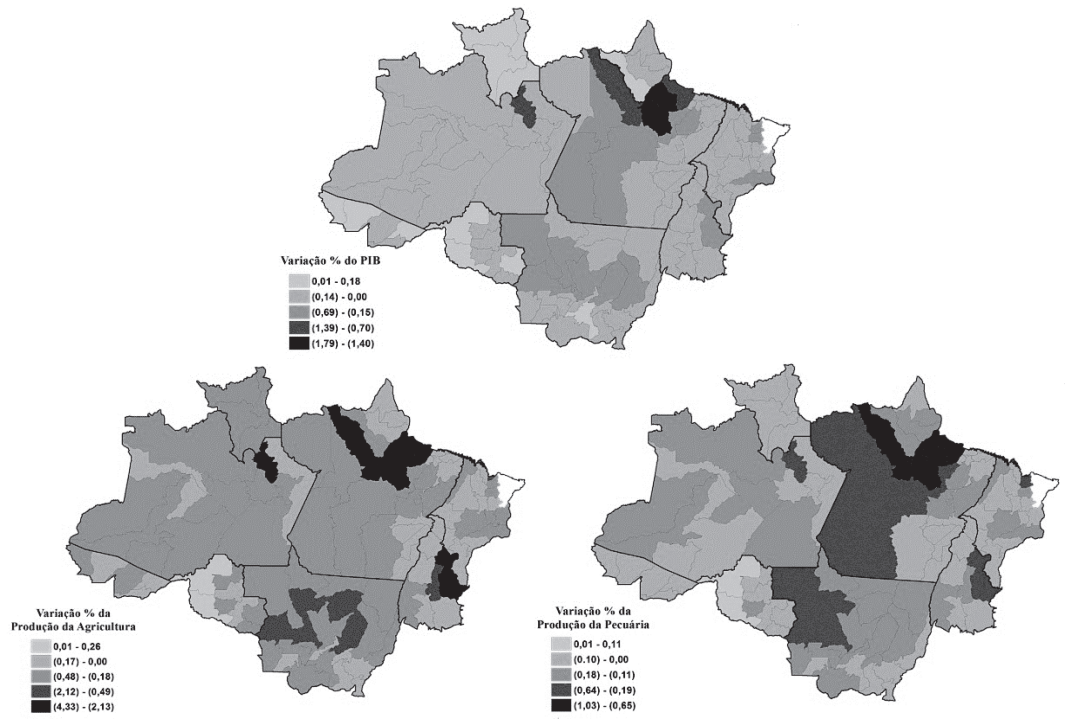

Figura 6 - Resultados das simulações: efeito do controle do desmatamento sobre o PIB, produção da Agricultura e Pecuária (var. \% acumulada de 2012 a 2020)

Fonte: Elaboração própria com base nos resultados do modelo REGIA. 
As regiões de Boa Vista, Nordeste de Roraima, e Caracaraí, assim como Cuiabá, apresentariam um pequeno aumento no PIB real, acima de $0,07 \%$, mesmo com a política de controle do desmatamento na Amazônia. As quatro regióes apresentam pequena taxa de desmatamento no cenário de referência, e tanto o Nordeste de Roraima como Caracaraí são regiões dependentes da agricultura, embora possuam uma economia com elevada participação do governo. Já Boa Vista e Cuiabá apresentam uma economia voltada ao setor de serviços. De modo geral, as regiões mais dependentes da agropecuária seriam as mais afetadas pela política de controle de desmatamento, com um deslocamento relativo da produção em direção às regiões menos afetadas diretamente pela política.

A Figura 7 apresenta os impactos sobre o investimento e consumo das famílias. O investimento real na Amazônia teria um acréscimo na maioria das regiões. Este resultado indica que o efeito substituição do fator terra em direção aos demais fatores, capital e trabalho, seria mais forte do que o efeito atividade (queda na produção). Regiões que apresentariam as maiores quedas de produção como Portel, Furos dos Breves, Almeirim e Arari se destacariam apresentando os maiores crescimentos do investimento da Amazônia. O consumo das famílias apresentaria o mesmo padrão que o investimento. Um dos efeitos esperados das políticas de controle do desmatamento seria a intensificação do uso de capital e trabalho por hectare, o que contribuiria diretamente para o aumento da produtividade.
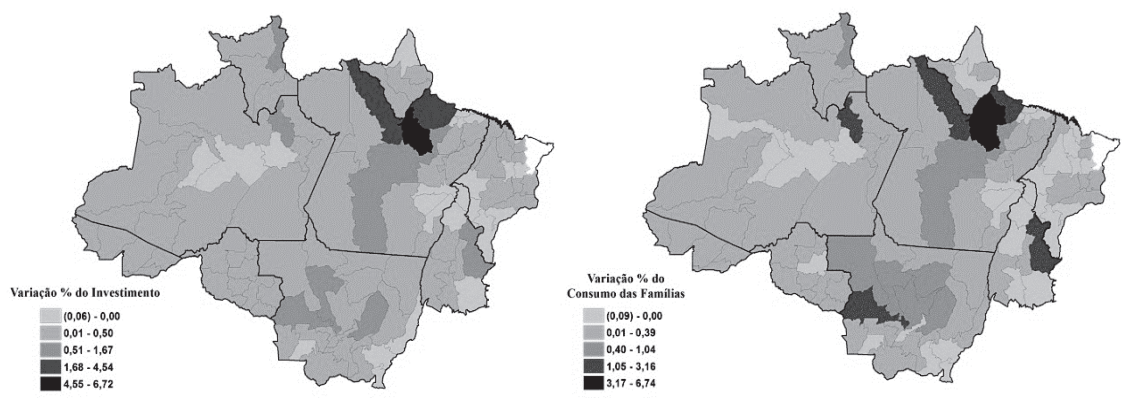

Figura 7 - Resultados das simulações: efeito do controle do desmatamento sobre investimento e consumo das famílias (var. \% acumulada de 2012 2020)

Fonte: Elaboração própria com base nos resultados do modelo REGIA. 
Tabela 4 - Resultados das simulações: efeito do controle do desmatamento no Brasil, Amazônia Legal e Resto do Brasil (variação \% acumulada de 2012 a 2020).

\begin{tabular}{|c|c|c|c|c|}
\hline \multirow{7}{*}{ 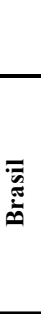 } & \multirow{2}{*}{$\begin{array}{l}\text { Variáveis } \\
\text { PIB real }\end{array}$} & \multirow{2}{*}{$\begin{array}{c}\begin{array}{c}\text { Variação } \\
(\%)\end{array} \\
-0,056\end{array}$} & \multicolumn{2}{|c|}{$\begin{array}{c}\text { Intervalo de Confiança } \\
\qquad(90 \%)\end{array}$} \\
\hline & & & $-0,091$ & $-0,021$ \\
\hline & Consumo real das famílias & $-0,040$ & $-0,069$ & $-0,012$ \\
\hline & Investimento Real & $-0,028$ & $-0,048$ & $-0,009$ \\
\hline & Volume de exportações & $-0,079$ & $-0,125$ & $-0,033$ \\
\hline & Volume de importações & 0,129 & 0,056 & 0,201 \\
\hline & Emprego Agregado & $-0,047$ & $-0,077$ & $-0,017$ \\
\hline \multirow{6}{*}{$\sum$} & PIB real & $-0,074$ & $-0,125$ & $-0,023$ \\
\hline & Consumo real das famílias & 0,101 & 0,055 & 0,146 \\
\hline & Investimento Real & 0,142 & 0,068 & 0,216 \\
\hline & Volume de exportações & $-0,104$ & $-0,164$ & $-0,044$ \\
\hline & Volume de importações & 0,255 & 0,113 & 0,399 \\
\hline & Emprego Agregado & 0,149 & 0,073 & 0,226 \\
\hline \multirow{6}{*}{ 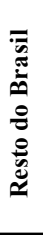 } & PIB real & $-0,054$ & $-0,088$ & $-0,020$ \\
\hline & Consumo real das famílias & $-0,065$ & $-0,105$ & $-0,025$ \\
\hline & Investimento Real & $-0,044$ & $-0,072$ & $-0,016$ \\
\hline & Volume de exportações & $-0,075$ & $-0,120$ & $-0,032$ \\
\hline & Volume de importações & 0,112 & 0,049 & 0,176 \\
\hline & Emprego Agregado & $-0,065$ & $-0,105$ & $-0,025$ \\
\hline
\end{tabular}

Fonte: Elaboração própria com base nos resultados do modelo REGIA.

A Tabela 4 apresenta os principais resultados agregados da política de controle do desmatamento. As simulações mostram perdas nos principais indicadores nacionais. O PIB nacional apresentaria uma redução acumulada de $0,05 \%$ até 2020 , o que representa uma redução marginal de 0,006\% a.a., que se explica pelas perdas de produção da Amazônia. Soma-se a isso, a queda da atividade no restante do Brasil devido às relações de interdependência comercial com a Amazônia. O restante do Brasil, por sua vez, embora não seja considerado nos choques de restrição ao desmatamento, é afetado indiretamente pela política, apresentando variações negativas na maioria dos indicadores selecionados. A Amazônia é importante fornecedora de insumos (principalmente agropecuários) para o restante do Brasil. Como esses produtos apresentam aumento de preços, isto gera aumento de custos e queda da atividade dos setores do restante do Brasil. 


\section{Considerações finais}

Este artigo teve por objetivo estudar a contribuição da floresta desmatada para a economia da Amazônia Legal entre 2006 e 2011, assim como analisar os efeitos de uma política de controle do desmatamento no período de 2012 a 2020. Para isso, utilizou-se um modelo EGC inter-regional, especialmente construído para capturar as especificidades e heterogeneidade da região. No modelo, modificações na disponibilidade de terras associadas ao desmatamento, afetam as possibilidades de produção nas regiões da Amazônia, provocando deslocamentos na produção, assim como alterações nos padrões da produção agrícola e de comércio na região. Desse modo, as estimativas mensuram o custo de oportunidade no que se refere ao desmatamento na Amazônia Legal.

Cabe ressaltar que, apesar dos resultados das simulações indicarem a contribuição positiva do desmatamento entre 2006 e 2011 para o crescimento econômico nas regiões da Amazônia, sua pequena magnitude indica que a contribuição econômica do desmatamento ao longo desse período foi pouco significativa. Pode-se concluir, portanto, que o trade-off entre preservação ambiental e crescimento econômico pode não ser tão relevante para o caso do desmatamento na Amazônia, uma vez que este pouco contribuiria para o crescimento da região. Este resultado é ainda reforçado pelos impactos econômicos de uma política hipotética de controle do desmatamento, que sugerem uma perda apenas marginal sobre o crescimento econômico das regiões da Amazônia, assim como no restante do Brasil. Em resumo, ambos os resultados apontam para uma baixa contribuição econômica do desmatamento. Por outro lado, um dos efeitos esperados de políticas de controle do desmatamento seria o incentivo para elevação do uso de capital e trabalho por hectare, o que contribuiria diretamente para o aumento da produtividade das atividades agrícolas e da pecuária nessas regiões. Assim, políticas públicas que possibilitem a elevação da oferta de capital físico e técnicas produtivas devem ser um complemento prioritário para políticas de controle do desmatamento.

Um resultado importante, que pode subsidiar políticas públicas para a região, é a estimativa de que um aumento de produtividade da agropecuária na Amazônia Legal de pouco mais de $1 \%$ ao ano seria suficiente para compensar os ganhos projetados decorrentes da ex- 
pansão da ocupação de terras. Este parece ser um elemento bastante factível, tendo em vista o histórico de crescimento da produtividade da terra nos últimos anos (3,26\% ao ano entre 2000 e 2005). Isso sugere que o "endurecimento" de políticas de combate ao desmatamento traria pouco efeito em termos de crescimento econômico na região. Essa política, atrelada a investimentos em tecnologias que aumentem a produtividade da região, poderia conciliar uma maior produção agropecuária junto à manutenção da floresta e todos os seus benefícios. Pois com maior produtividade, a mesma ou uma maior produção poderia ser obtida sem a necessidade de se aumentar o fator terra e, portanto, sem aumentar o desmatamento da Amazônia para a expansão da fronteira agrícola.

Em termos metodológicos, o modelo REGIA se destaca na literatura por sua detalhada base de dados e desagregação regional. Desenvolvimentos futuros apontam para a inclusão de elementos de dinâmica recursiva, modelagem explícita de uso da terra, e desagregação regional para outros estados brasileiros. A dinâmica recursiva incluiria explicitamente a dimensão temporal ao modelo, permitindo ajustamentos no estoque de capital, mercado de trabalho e mercado de terra. Também permitiria que a política de desmatamento fosse simulada ano após ano, mostrando a trajetória dos resultados ao longo do tempo. A inclusão da modelagem explícita de uso da terra possibilitaria considerar as possibilidades de substituição entre os diferentes usos da terra: cultivo, pecuária e floresta plantada, dependendo da rentabilidade de cada ocupação. Além disso, a inclusão no modelo dos demais estados brasileiros, permitiria avaliar o deslocamento da produção para outras regiões.

\section{Referências}

AGUIAR, A.P. et al. Spatial statistical analysis of land-use determinants in the Brazilian Amazonia: Exploring intra-regional heterogeneity. Ecological Modelling, 209, 2007. p.169-188.

ALENCAR, A. et al. Desmatamento na Amazônia: indo além da emergência crônica. Manaus, Instituto de Pesquisa Ambiental da Amazônia (IPAM), pp.89, 2004.

ANDERSEN, L. E.; REIS, E. J. Deforestation, Development, and Government Policy in the Brazilian Amazon: An Econometric Analysis. Texto para Discussão n. 513. Rio de Janeiro: Ipea, set. 1997.

ASSUNÇÃO, J. et al. Deforestation Slowdown in the Legal Amazon: Prices or Policies? Climate policy iniciative. Working paper, 2012. Disponível em http://climate policyinitiative.org/publication/ deforestation-slowdown-in-the-legal-amazon-prices-or-policie/. Acesso em 02 de outubro de 2012. 
BARONA, E. et al. The role of pasture and soybean in deforestation of the Brazilian Amazon. Environmental Research Letters, n. 5, 2010.

BECKER, B.K. Geopolítica da Amazônia. Estudos Avançados, 19 (53), 2005.

BICKEL U.; DROS J. M. The Impacts of Soybean Cultivation on Brazilian Ecoystems (Bonn: AIDEnvironment-WWF) p 33, Disponível em: http://assets.panda.org/downloads/ impactsofsoybean. pdf. Acesso em 02 de outubro de 2012.

BINSWANGER, H.P. Brazilian policies that encourage deforestation in the Amazon. World Development 19 (7), 821-829, 1991.

BITTENCOURT, F. R. Modelagem Dinâmica de Distribuição de Metas de Redução de Desmatamento, Estimativas de Potencial de Emissão de Gases de Efeito Estufa e de Receitas Financeiras via REDD+ em Niveis Subnacionais. 2011.230 p. Tese (Doutorado em Saneamento, Meio Ambiente e Recursos Hídricos) - Escola de Engenharia da Universidade Federal de Minas Gerais, Belo Horizonte, 2011.

CARVALHO, G. O.et al. Frontier expansion in the Amazon. Balancing development and sustainability. Environment Sci. Policy Sustainable Dev. 44 p.32-42, 2002.

CARVALHO, T. S. Uso do Solo e Desmatamento nas Regiões da Amazônia Legal Brasileira: condicionantes econômicos e impactos de políticas públicas, 2014, 219 p. (Tese de Doutorado). Belo Horizonte: Centro de Desenvolvimento e Planejamento Regional (Cedeplar) Universidade Federal de Minas Gerais, 2014.

CASTRO, E. Dinâmica socioeconômica e desmatamento na Amazônia. Novos Cadernos NAEA, v. 8, n. 2, p. 5-39, Pará: dez. 2005.

CATTANEO, A. Deforestation in the Brazilian Amazon: Comparing the impacts of Macroeconomics Shocks, Land Tenure, and Technological Change. Land Economics, vol. 77, n.2, p. 219-140, 2001.

CHOMITZ, K. M.; THOMAS, T. S. Geographic Patterns of Land Use and Land Intensity in the Brazilian Amazon (Washington, DC: World Bank) p 50, 2001. Disponível em http://ideas.repec.org/p/ wbk/wbrwps/2687.html. Acesso em 26 de setembro de 2012.

DARWIN, R. et al. World Agriculture and Climate Change: economic adaptations. Agricultural Economic Report, n. 703, 98 p., 1995.

DEVUYST, E. A.; PRECKEL, P. V. Sensitivity Analysis Revisited: A Quadrature based Approach. Journal of Policy Modeling, vol. 19, n. 2, p. 175-185, 1997.

DOMINGUES, E.P. Dimensão Regional e Setorial da Integração Brasileira na Área de Livre Comércio das Américas. 2002. 228 p. (CDD-338.9). Tese (Doutorado em Economia) - Faculdade de Economia, Administração e Contabilidade da Universidade de São Paulo, São Paulo, 2002.

FEARNSIDE, P. M. Deforestation in Brazilian Amazonia: history, rates and consequences. Conservation Biology, 19(3), p. 680-688, 2005.

FERREIRA FILHO, J. B. S.; HORRIDGE, M. Ethanol Expasion and Indirect Land Use Change in Brazil, Melbourne, Monash University, CoPs, 2011. Disponível em: $<\underline{\mathrm{http}}: / /$ www.eacquality.net/ fileadmin/eac_quality/user_documents/3 pdf/Ethanol_expansion_and_indirect_land_use_change in_Brazil.pdf $>$. Acesso em: ago. 2011.

FERREIRA, A.M.M.; SALATI, E. Forças de transformação do ecossistema amazônico. Estudos Avançados, 19 (54), 2005.

FERREIRA, L.V. et al. O desmatamento na Amazônia e a importância das áreas protegidas. Estudos Avançados, v.19, n. 53, 2005.

Food and Agriculture Organization of the United Nations (FAO) Global Forest Resources Assessment 2010. Food and Agriculture Organization of the United Nations, Rome, 2010.

GEIST, H.; LAMBIN, E. F. Global land-use and cover change: What have we learned so far? Global Change Newsletter, p.46, 2002.

GREENE, W. H. Econometric Analysis. 5.ed. Upper Saddle River, N.J.: Prentice Hall, 2003. 1026 p.

Estud. Econ., São Paulo, vol.46, n.2, p. 499-531, abr.-jun. 2016 
HADDAD, E. A. Regional Inequality and Structural Changes: Lessons from the Brazilian Experience. Aldershot: Ashgate. 1999.

HORRIGDE, M. Preparing a TERM bottom-up regional database. Preliminary Draft, Centre of Policy Studies, Monash University, 2006.

IGLIORI, D.C. Deforestation, Growth and Agglomeration Effects: Evidence from Agriculture in the Brazilian Amazon. University of Cambridge, Department of Land Economy (Texto para Discussão, 28) 2008. Disponível em: <http://ideas.repec.org/p/wiw/wiwrsa/ ersa06p719.html>. Acesso em: 23 jan. 2009

INSTITUTO BRASILEIRO DE GEOGRAFIA E ESTATÍSTICA - IBGE. Censo Agropecuário 2006. Rio de Janeiro: IBGE, 2006.

INSTITUTO NACIONAL DE PESQUISAS ESPACIAIS - INPE. Projeto Prodes Monitoramento da Floresta Amazônica Brasileira por Satélite. 2009. Disponível em: < http://www.obt.inpe.br/ prodes/ index.html>. Acesso em 23 de setembro de 2012.

INSTITUTO NACIONAL DE PESQUISAS ESPACIAIS (INPE); EMPRESA BRASILEIRA DE PESQUISA AGROPECUÁRIA (EMBRAPA). TerraClass - Levantamento de Informações de uso e cobertura da terra na Amazônia, setembro de 2011.

JARAMILlO, C. F. e KELLY, T. Deforestation and Property Rights in Latin America.Washington, D.C.: Inter-American Development Bank. 1999. Disponível em: <http://idbdocs.iadb.org/wsdocs/ getdocument.aspx?docnum=359769> . Acesso em 04 de outubro de 2012.

KAIMOWITZ, D.et al. Hamburger connection files Amazon destruction. Bangon, Indonesia: Center for International Forest Research, 2004.

KRUGMAN, P. Scale Economics, product differentiation, and the pattern of trade, American Economic Review, v. 70, 1980.

MARGULIS, S. Causas do desmatamento da Amazônia brasileira. Banco Mundial, 2003.

MATTEI, F. E. E. Modeling Linkages between Climate Policy and Land Use: An overview. Working Papers WP24. Italy, 2007.

MERTENS, B.et al. Crossing spatial analyses and livestock economics to understand deforestation process in Brazilian Amazon: the case of São Felix do Xingu in South Pará. Agricultural Economics, n. 27, p. 269-294, 2002.

MILLER, R.; BLAIR, P. Input-Output analysis: foundations and extensions. New Jersey: Prentice-Hall, 2009. 782p.

Ministério de Ciência e Tecnologia. Inventário Brasileiro de Emissões Antrópicas por Fontes e Remoções por Sumidouros de Gases de Efeito Estufa não Controlados pelo Protocolo de Montreal. Brasília: Ministério de Ciência e Tecnologia, 2010.

MIRAGAYA, J. Demanda mundial de carne bovina tem provocado o desmatamento na Amazônia. T\&C Amazônia, ano VI, n 14, 2008.

NEPSTAD, D.et al. Road paving, fire regime feedbacks, and the future of Amazon forests. Forest Ecology and Management, n. 154, p. 395-407, 2001

NEPSTAD, D.et al. The end of deforestation in the Brazilian Amazon. Science 326 (5958), p. 1350-1351, 2009.

OLIVEIRA JUNIOR, et al. Análise da área desmatada municipal na Amazônia Brasileira no período 2000 - 2004: Uma abordagem com modelos não-lineares, Economia Aplicada, vol. 14, n. 3, p. 395-411, 2010.

PATTANAYAK, S. K.et al. Climate Change and Conservation in Brazil: CGE Evaluation of Health and Wealth Impacts, Economic Geography and Color Maps, vol. 9, n.2, 2009.

PERES, C.A. et al. Biodiversity conservation in human-modified Amazonian forest landscapes. Biological Conservation n. 143, p. 2314-2327, 2010.

Estud. Econ., São Paulo, vol.46, n.2, p. 499-531, abr.-jun. 2016 
PFAFF, A. S.P. What Drives Deforestation in the Brazilian Amazon? Evidence from satellite and Socioeconomic Data. 1997 (Working Paper, 1772). Disponível em: < http://wwwwds.worldbank.org/ servlet/WDSContentServer/WDSP/IB/1997/05/01/000009265_3980313101835/Rendered/PDF/ multi_page.pdf>.Acesso em 26 de setembro de 2012.

REIS, E.; MARGULLIS, S. Options for slowing Amazon jungle clearing. IN: DORNBUSCH, R., POTERBA, J. Economic Policy Responses to Global Warming, Cambridge, MA, MIT Press, 1991.

RIVERO, S. et al. Pecuária e Desmatamento: Uma Análise das Principais Causas Diretas do Desmatamento na Amazônia. Nova Economia, 19(1), pp. 41-66, 2009.

SOARES-FILHO, B. S. et al. Cenário de Desmatamento para a Amazônia. Estudos Avançados, v. 19, n. 54, p. 137-152, 2005.

SOARES-FILHO, B. S.et al. Redução das Emissões de Carbono do Desmatamento no Brasil: O papel do programa Áreas Protegidas da Amazônia (ARPA), WWF, 2009.

SOUZA, R. A. et al. Spatial variation of deforestation rates in the Brazilian Amazon: A complex theater for agrarian technology, agrarian structure and governance by surveillance. Land Use Policy, n. 30, p. 915-924, 2012.

WALKER, R. et al. Deforestation and cattle ranching in the Brazilian Amazon: external capital and household processes. World Development 28 (4), 683-699.

\section{ANEXO 1 - Especificação simplificada do núcleo central do modelo REGIA}

Supõe-se uma economia aberta de $J$ setores e $R$ regióes. Para produzir $C$ commodities na economia, os setores utilizam insumos intermediários de origem doméstica e importada $(s=D$ e $M)$, assim como $f$ fatores de produção: trabalho, capital e terra $(f=L, K e T)$. Os Quadros 1 e 2 mostram as equações do módulo central do modelo REGIA e sua notação. Os sobrescritos descrevem as dimensões de uma variável. As equações são definidas para cada região do modelo (suprimimos o subscrito de região por simplificação). Por exemplo, $X_{0}^{D c j}$ representa a quantidade produzida domesticamente da commodity $c$ pelo setor $j$ na região $r$. 
Quadro 1 - Representação das equações principais do modelo REGIA (definidas para cada região $\mathrm{R}$ do modelo)

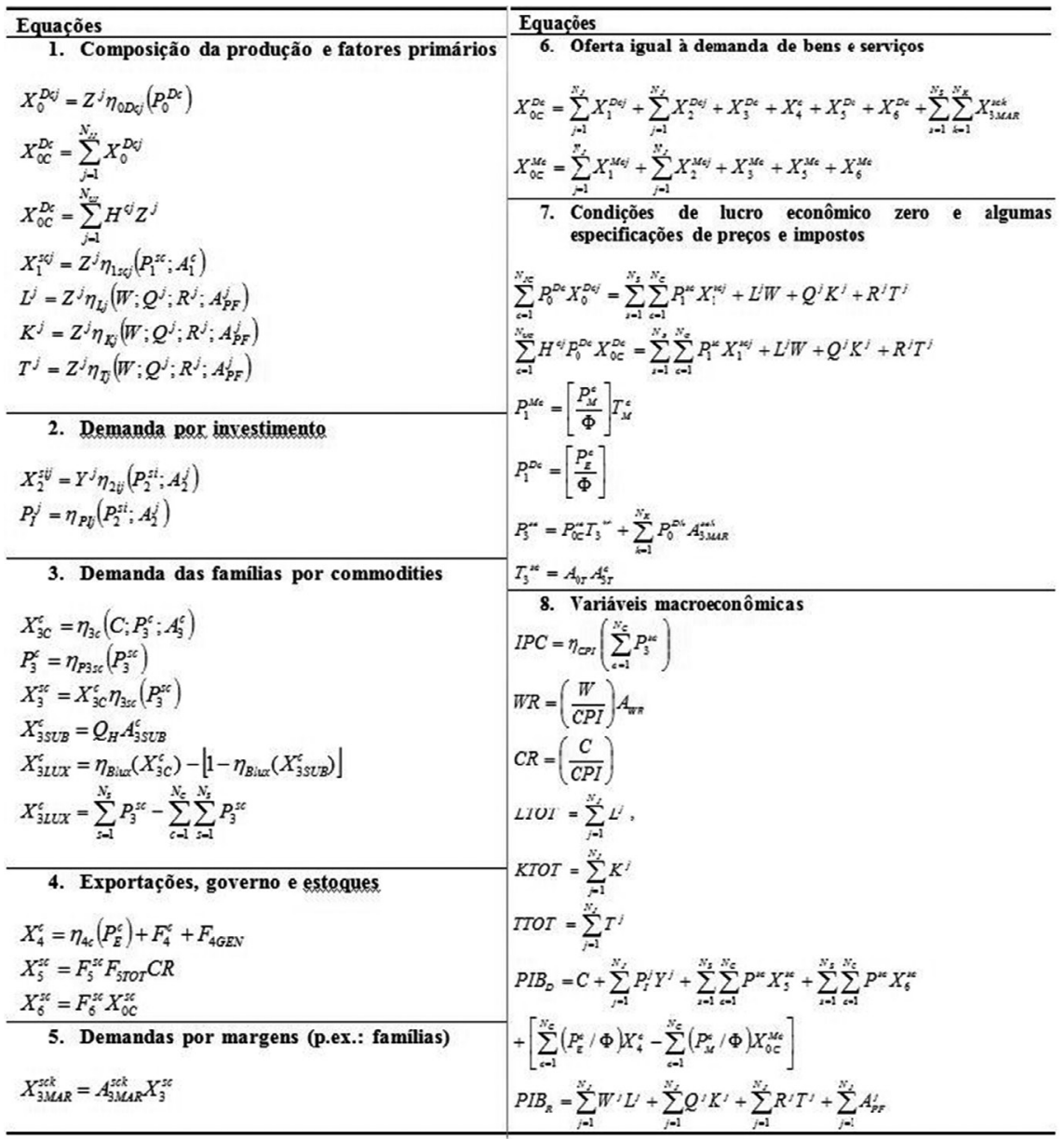


Quadro 2 - Notação do modelo estilizado (definidas para cada região $\mathrm{R}$ do modelo)

\begin{tabular}{|c|c|c|c|}
\hline \multicolumn{4}{|c|}{ Descrição das variáveis } \\
\hline$X_{0}^{D j j}$ & $\begin{array}{l}\text { Produção de bens domésticos por } \\
\text { setor }\end{array}$ & $T_{3}^{s c}$ & $\begin{array}{l}\text { Poder dos impostos sobre o consumo } \\
\text { das familias }\end{array}$ \\
\hline$X_{O C}^{D C}$ & Produção total dos bens domésticos & $I P C$ & Índice de preço do consumidor \\
\hline$X_{O C}^{D C}$ & Produção total dos bens domésticos & $W$ & Salánio nominal médio \\
\hline$X_{1}^{s c j}$ & Demanda de insumos intermediános & $C R$ & Consumo real das familias \\
\hline$L^{j}$ & Emprego por setor & TTOT & Oferta total de terra \\
\hline$Z^{j}$ & Nível de atividade no setor & $P I B_{D}$ & $\begin{array}{l}\text { Produto Intemo Bruto (ótica de } \\
\text { dispêndio) }\end{array}$ \\
\hline$R^{j}$ & Preço da terra por setor & $P I B_{R}$ & Produto Intemo Bruto (ótica de renda) \\
\hline$X_{2}^{s i j}$ & $\begin{array}{l}\text { Demanda de insumos para a criação de } \\
\text { capital }\end{array}$ & $C$ & Dispêndio total das familias \\
\hline$P_{I}^{j}$ & Custo unitánio do capital por setor & $W R$ & Salánio real \\
\hline$X_{3 C}^{c}$ & Demanda das familias por bens & $Q_{H}$ & Número de familias \\
\hline$P_{3}^{c}$ & $\begin{array}{l}\text { Preço dos bens demandados pelas } \\
\text { familias }\end{array}$ & $P_{E}^{c}$ & $\begin{array}{l}\text { Preço em moeda estrangeira para } \\
\text { exportação }\end{array}$ \\
\hline$X_{3}^{s c}$ & Demanda das familias por $c$ e $s$ & $P_{M}^{c}$ & $\begin{array}{l}\text { Preço em moeda estrangeira para } \\
\text { importação }\end{array}$ \\
\hline$A_{3 S U B}^{c}$ & $\begin{array}{l}\text { Mudança de preferência na demanda } \\
\text { por bens de subsistência }\end{array}$ & $T_{M}^{c}$ & $\begin{array}{l}\text { Poder de tarifa sobre a importação de } \\
\text { commodities }\end{array}$ \\
\hline$X_{3 S U B}^{c}$ & $\begin{array}{l}\text { Demanda das familias por bens de } \\
\text { subsistência }\end{array}$ & $\Phi$ & Taxa de câmbio \\
\hline$X_{3 L U X}^{c}$ & $\begin{array}{l}\text { Demanda das familias por bens de } \\
\text { luxo }\end{array}$ & $\eta$ & Elasticidades e parâmetros do modelo \\
\hline$F_{4}^{c}$ & $\begin{array}{l}\text { Deslocamento da função de demanda } \\
\text { das exportações }\end{array}$ & $A_{1}^{c}$ & $\begin{array}{l}\text { Mudança tecnológica no uso de } \\
\text { insumos }\end{array}$ \\
\hline$X_{5}^{s c}$ & Demanda do govemo por $c$ es & $A_{P F}^{j}$ & Mudança tecnológica do fator primánio \\
\hline$X_{6}^{s c}$ & Variação de estoque por bens & $A_{2}^{j}$ & $\begin{array}{l}\text { Mudança tecnológica de insumos para } \\
\text { o novo capital }\end{array}$ \\
\hline$X_{3 M A R}^{s c k}$ & Demandas das familias por margens & $A_{3}$ & Mudanças nas preferências das familias \\
\hline$X_{4}^{c}$ & Exportação de commodities & $A_{3 M U R}^{s c k}$ & $\begin{array}{l}\text { Mudanças nas preferências das familias } \\
\text { pela demanda de margens }\end{array}$ \\
\hline$X_{\infty c}^{M c}$ & Total de importação de commodities & $F_{4 G E N}$ & $\begin{array}{l}\text { Deslocamento total da função de } \\
\text { demanda das exportações }\end{array}$ \\
\hline$Q^{j}$ & $\begin{array}{l}\text { Preço da renda do capital no setor } \\
\text { (multiprodução) }\end{array}$ & $F_{5}^{s c}$ & Deslocamento do consumo do govemo \\
\hline$Q^{j}$ & Preço da renda do capital no setor & $F_{5 T O T}$ & $\begin{array}{l}\text { Deslocamento total do consumo do } \\
\text { govemo }\end{array}$ \\
\hline$P_{1}^{M c}$ & Preço básico de bens importados & $F_{6}^{s c}$ & Deslocamento da variação de estoque \\
\hline$P_{1}^{D e}$ & Preço básico de bens domésticos & $A_{O T}$ & $\begin{array}{l}\text { Deslocamento dos impostos sobre } \\
\text { conssumo de todos os usuánios }\end{array}$ \\
\hline$P_{3}^{s c}$ & $\begin{array}{l}\text { Preço de compra dos bens } \\
\text { demandados pelas familias }\end{array}$ & $A_{3 T}^{c}$ & $\begin{array}{l}\text { Deslocamento dos impostos sobre } \\
\text { consumoo das familias }\end{array}$ \\
\hline
\end{tabular}

